\title{
The Contribution of Pharmaceutical Innovation to Longevity Growth in Germany and France
}

\author{
Frank Lichtenberg
}

\author{
CESIFO WORKING PAPER No. 3095
}

Category 6: Fiscal Policy, Macroeconomics and Growth JUNE 2010

\footnotetext{
An electronic version of the paper may be downloaded

- from the SSRN website: Www.SSRN.com

- from the RePEc website: $\quad$ www.RePEc.org

- from the CESifo website: www.CESifo-group.org/wp
} 


\title{
The Contribution of Pharmaceutical Innovation to Longevity Growth in Germany and France
}

\begin{abstract}
I investigate the contribution of pharmaceutical innovation to recent longevity growth in Germany and France. First, I examine the effect of the vintage of prescription drugs (and other variables) on the life expectancy and age-adjusted mortality rates of residents of Germany, using longitudinal, annual, state-level data during the period 2000-2007. The estimates imply that almost half of the 1.7-year increase in German life expectancy during the period 2000-2007 was due to the replacement of older drugs by newer drugs. Next, I examine the effect of the vintage of chemotherapy treatments on age-adjusted cancer mortality rates of residents of France, using longitudinal, annual, cancer-site-level data during the period 20022006. The estimates imply that chemotherapy innovation accounted for at least one-sixth of the decline in French cancer mortality rates, and may have accounted for as much as half of the decline.
\end{abstract}

JEL-Code: C20, H51, I10, I12, J10, L65, O00.

\author{
Frank Lichtenberg \\ Columbia University \\ frank.lichtenberg@columbia.edu
}

This research was supported by Merck Sharp \& Dohme Corp. and by Servier Laboratories. The sponsors placed no restrictions or limitations on data, methods, or conclusions, and had no right of review or control over the outcome of the research. 


\section{Introduction}

Longevity increase is an important part of economic growth and development. Nordhaus (2002) estimated that, "to a first approximation, the economic value of increases in longevity over the twentieth century is about as large as the value of measured growth in non-health goods and services" (p. 17). Murphy and Topel (2005) observed that "the historical gains from increased longevity have been enormous. Over the 20th century, cumulative gains in [U.S.] life expectancy were worth over \$1.2 million per person for both men and women. Between 1970 and 2000 increased longevity added about $\$ 3.2$ trillion per year to national wealth, an uncounted value equal to about half of average annual GDP over the period." In its Human Development Reports, the United Nations Development Program ranks countries by their value of the Human Development Index, which is based on life expectancy at birth as well as on the adult literacy rate and per capita GDP.

Since the 1950s, economists have recognized that, in the long run, the rate of economic growth is determined by (indeed equal to) the rate of technological progress. In neoclassical growth models developed by Nobel laureate Robert Solow $(1956,1957)$ and colleagues, an economy will always converge towards a steady state rate of growth, which depends only on the rate of technological progress.

In early models of economic growth, the rate of technological progress was assumed to be given, or exogenous: technological progress was regarded as "manna from heaven." Economists began to relax this clearly unrealistic assumption in the 1980s, by developing socalled "endogenous growth models." In Paul Romer's (1990) model, "growth...is driven by technological change that arises from intentional [R\&D] investment decisions made by profitmaximizing agents." Jones (1998) argues that "technological progress [is] the ultimate driving force behind sustained economic growth" (p.2), and that "technological progress is driven by research and development (R\&D) in the advanced world" (p. 89).

Technological change may be either disembodied or embodied. Suppose firm X invests in $\mathrm{R} \& \mathrm{D}$, and that this investment results in a valuable discovery. If the technological advance is disembodied, consumers and other firms could benefit from the discovery without purchasing

\footnotetext{
${ }^{1}$ Growth may also be driven by technological change arising from R\&D investment by public organizations, e.g. the National Institutes of Health.
} 
firm X's goods or services; they could benefit just by reading or hearing about the discovery. However, if the technological advance is embodied, consumers and other firms must purchase firm X's goods or services to benefit from its discovery. Solow (1960, p 91): argued that "many if not most innovations need to be embodied in new kinds of durable equipment before they can be made effective. Improvements in technology affect output only to the extent that they are carried into practice either by net capital formation or by the replacement of old-fashioned equipment by the latest models..."2 Romer also assumes that technological progress is embodied in new goods: "new knowledge is translated into goods with practical value," and "a firm incurs fixed design or research and development costs when it creates a new good. It recovers those costs by selling the new good for a price that is higher than its constant cost of production." Grossman and Helpman (1993) argued that "innovative goods are better than older products simply because they provide more 'product services' in relation to their cost of production." Bresnahan and Gordon (1996) stated simply that "new goods are at the heart of economic progress," and Bils (2004) said that "much of economic growth occurs through growth in quality as new models of consumer goods replace older, sometimes inferior, models."

When technological progress is embodied in new goods, the welfare of consumers (and the productivity of producers) depends on the vintage of the goods (or inputs) they purchase. In this context, "vintage" refers to the year in which the good was first produced or sold. For example, the vintage of the drug simvastatin is 1993: that is the year it was approved by the FDA, and first sold. Solow was the first economist to develop a growth model that distinguished between vintages of (capital) goods. In Solow's model, new capital is more valuable than old capital because--since capital is produced based on known technology, and technology improves with time--new capital will be more productive than old capital. ${ }^{3}$ A number of econometric studies (Bahk and Gort (1993), Hulten (1992), Sakellaris and Wilson (2004)) have shown that manufacturing firms using later-vintage equipment have higher productivity.

The extent to which the welfare of consumers or the productivity of producers depends on the vintage of the goods they purchase should depend on the research intensity of those goods. The greater the research intensity of the goods, the greater the impact of their vintage on consumer welfare and producer productivity. According to the National Science Foundation, the

\footnotetext{
${ }^{2}$ We hypothesize that innovations may be embodied in nondurable goods (e.g. drugs) and services as well as in durable equipment.

${ }^{3}$ http://en.wikipedia.org/wiki/Exogenous_growth_model
} 
pharmaceutical and medical devices industries are the most research intensive industries in the economy. ${ }^{4}$

In the next section, I will investigate the effect of the vintage of prescription drugs (and other variables) on the life expectancy and age-adjusted mortality rates of residents of Germany, using longitudinal, annual, state-level data during the period 2000-2007. The analysis will be based on data on the utilization of over 600 active ingredients in a variety of drug classes, which account for about 250 million prescriptions (43\% of all prescriptions in Germany) per year.

In the following section, I will investigate the effect of the vintage of chemotherapy treatments on age-adjusted cancer mortality rates of residents of France, using longitudinal, annual, cancer-site (breast, colon, lung, etc.) -level data during the period 2002-2006. ${ }^{5}$ The analysis will be based on data on the utilization of 11 cancer drugs by about 4000 cancer patients per year.

\section{Germany longevity}

\section{A. Econometric model}

I will estimate models of the following form:

$$
\text { OUTCOME }_{\mathrm{st}}=\beta \mathrm{VINTAGE}_{\mathrm{st}}+\gamma \mathrm{X}_{\mathrm{st}}+\alpha_{\mathrm{s}}+\delta_{\mathrm{t}}+\varepsilon_{\mathrm{st}}
$$

where OUTCOME is one of the following variables:

$\mathrm{LE}_{\mathrm{st}}=$ life expectancy at birth in state $\mathrm{s}$ in year $\mathrm{t}(\mathrm{s}=1, \ldots, 16 ; \mathrm{t}=$ $2000, \ldots, 2007)$

$\ln \_\mathrm{AAMORT}_{\mathrm{st}}=$ the $\log$ of the age-adjusted mortality rate in state $\mathrm{s}$ in year $\mathrm{t}^{6}$

\footnotetext{
${ }^{4}$ In 1997, "medical substances and devices firms had by far the highest combined R\&D intensity at 11.8 percent,...well above the 4.2-percent average for all 500 top 1997 R\&D spenders combined. The information and electronics sector ranked second in intensity at 7.0 percent." The pattern of $1997 \mathrm{R} \& \mathrm{D}$ spending per employee is similar to that for R\&D intensity, with medical substances and devices again the highest at $\$ 29,095$ per employee. Information and electronics is second at $\$ 16,381$. Combined, the top $5001997 \mathrm{R} \& \mathrm{D}$ firms spent $\$ 10,457$ per employee.

${ }^{5}$ Cancer was the cause of about 30\% of deaths in France in 2006.

${ }^{6}$ Age-adjusted death rates are weighted averages of age-specific death rates, where the weights represent a fixed population by age. They are used to compare relative mortality risk among groups and over time. An age-adjusted rate represents the rate that would have existed had the age-specific rates of the particular year prevailed in a population whose age distribution was the same as that of the fixed population.
} 
VINTAGE is one of the following variables:

FDA_YEAR st $_{\text {s }}=$ the (weighted) mean FDA approval year of ingredients contained in prescriptions consumed in state $\mathrm{s}$ in year $\mathrm{t}$

POST $1990 \% \%_{\mathrm{st}}=$ the percent of prescriptions consumed in state $\mathrm{s}$ in year $\mathrm{t}$ that contained ingredients approved by the FDA after 1990

POST $1995 \% \%_{\text {st }}=$ the percent of prescriptions consumed in state $\mathrm{s}$ in year $\mathrm{t}$ that contained ingredients approved by the FDA after 1995

and $\mathrm{X}$ includes a subset of the following variables:

$\ln$ GDP $_{\mathrm{st}}=$ the log of GDP per person in state $\mathrm{s}$ in year $\mathrm{t}$

$\mathrm{UNEMP}_{\mathrm{st}}=$ the unemployment rate in state $\mathrm{s}$ in year $\mathrm{t}$

ln_N_RX $\mathrm{St}_{\mathrm{st}}=$ the $\log$ of the number of prescriptions per person in state $\mathrm{s}$ in year $\mathrm{t}$

$\ln _{-}$NOTIF_DISEASES st $_{2}=$ the $\log$ of the number of notifiable diseases per 100,000 persons in state $\mathrm{s}$ in year $\mathrm{t}$

$\ln \_\operatorname{AIDS}_{\mathrm{st}}=$ the $\log$ of the number of new AIDS cases per 100,000 persons in state $\mathrm{s}$ in year $\mathrm{t}$

$\alpha_{\mathrm{s}}$ and $\delta_{\mathrm{t}}$ represent state fixed effects and year fixed effects, respectively. Due to the inclusion of these effects, eq. (1) is a difference-in-differences model. A significant negative drug vintage coefficient $(\beta)$ in a model in which the dependent variable is life expectancy would indicate that states that had above-average increases in drug vintage had above-average increases in life expectancy, controlling for other regressors.

Eq. (1) will be estimated by weighted least squares (WLS), weighting by pop st, state s's population in year $\mathrm{t}$. The estimation procedure will account for clustering of disturbances within states.

The drug vintage measure FDA_YEAR will be constructed as follows:

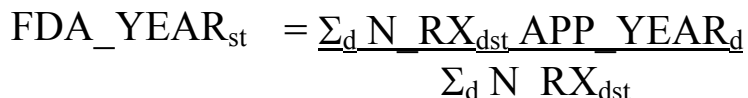

$$
\Sigma_{\mathrm{d}} \mathrm{N}_{-} \mathrm{RX}_{\mathrm{dst}}
$$


where

N_RX $\mathrm{Rst}_{\mathrm{dst}}=$ the number of prescriptions for drug $\mathrm{d}$ in state $\mathrm{s}$ in year $\mathrm{t}$

APP_YEAR I $_{d}=$ the year in which the active ingredient of drug $d$ was first approved by the $\mathrm{FDA}^{7}$

The drug vintage measure POST1990\% will be constructed as follows:

$$
\operatorname{POST} 1990 \% \%_{\text {st }}=\underline{\Sigma}_{\underline{d}} \frac{\mathrm{N} \_\mathrm{RX}}{\mathrm{dst}} \frac{\mathrm{APP} \text { YEAR GT } 1990_{\mathrm{d}}}{\sum_{\mathrm{d}} \mathrm{N}_{-} \mathrm{RX}_{\mathrm{dst}}}
$$

where

APP_YEAR_GT_1990 $0_{d}=1$ if the active ingredient of drug $d$ was first approved by the FDA after 1990

$$
=0 \text { otherwise }
$$

The drug vintage measure POST1995\% will be constructed as follows:

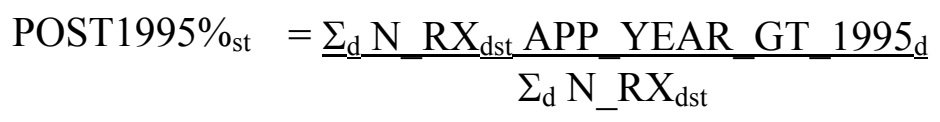

where

APP_YEAR_GT_1995 $=1$ if the active ingredient of drug $\mathrm{d}$ was first approved by the FDA after 1995

$$
=0 \text { otherwise }
$$

\section{B. Data and descriptive statistics}

Pharmaceutical data. Data on the number of prescriptions, by drug, state, and year $\left(\mathrm{N}_{-} \mathrm{RX}_{\mathrm{dst}}\right)$ were obtained from the IMS Health National Prescription Analysis database (http://www.imshealth.de/sixcms/detail.php/375), which covers more than $99 \%$ of prescriptions reimbursed by German Sick Funds. It does not contain drugs used in a hospital, drugs completely paid out-of-pocket, and drugs prescribed for members of private health insurance companies (approximately $10 \%$ of the German population, particularly high-income employees, self-

\footnotetext{
${ }^{7}$ If drug d contains 2 or more active ingredients, APP_YEAR ${ }_{d}$ is the mean of the years in which the active ingredients of drug $\mathrm{d}$ were first approved by the FDA.
} 
employed persons, military, and government officials). We were unable to obtain data on all drugs sold in Germany. Data were available for drugs included in the following drug classes ${ }^{8}$ :

- Cardiovascular $\left(\mathrm{C}^{* * *}\right)$

- Oncology (A04A, L***, B03A, B03C, V03D)

- Parkinson (N04A)

- Alzheimer/Dementia (N07D)

- Antidiabetics (A10*)

- Asthma/COPD (R03*)

- NSAID/Coxibs (M01A)

Appendix Table 1 compares 2008 data from our sample of drugs to data on all drugs dispensed in the Statutory Health Insurance system. Overall, our dataset provides information on about 250 million prescriptions per year for over 600 active ingredients, which account for $43 \%$ of total prescriptions and about $50 \%$ of total drug expenditure.

Data on the initial year of FDA approval of active ingredients $\left(\right.$ APP_YEAR $\left._{d}\right)$ were obtained from the Food and Drug Administration's Drugs@FDA database (http://www.fda.gov/Drugs/InformationOnDrugs/ucm079750.htm). ${ }^{9}$ We were able to determine the initial FDA approval year of products accounting for over $80 \%$ of the prescriptions in our sample.

Table 1 shows data on the top 25 drugs in our sample, ranked by the number of prescriptions during 2000-2008. Figure 1 shows data on the vintage distribution of prescriptions consumed during the period 2000-2008: it shows the percent of prescriptions consumed during 2000-2008 that were for drugs approved after year $t(t=1940, \ldots, 2010)$. About $75 \%$ of prescriptions were for drugs approved after 1975, 50\% were for drugs approved after 1986, and 25\% were for drugs approved after 1993.

Age-adjusted mortality and life expectancy data. We will analyze two different measures of longevity: the age-adjusted mortality rate, and life expectancy at birth. The Information System of the Federal Health Monitoring (http://www.gbe-bund.de/) provides data on age-adjusted mortality rates, by state and year. It also provides time-series data on life expectancy in Germany as a whole, but not life expectancy by state. However, it provides data on age-specific

\footnotetext{
${ }^{8}$ European Pharmaceutical Market Research Association (EphMRA) drug classification codes are shown in parentheses. The EphMRA classification is a modified modified version of the ATC classification. See http://www.ephmra.org/classification/anatomical-classification.aspx.

${ }^{9}$ The U.S. is the country in which many drugs are first launched. Also, it is difficult to obtain data on the date at which drugs were first launched in Germany.
} 
Table 1

Top 25 drugs in sample, ranked by number of prescriptions during 2000-2008

\begin{tabular}{|c|c|c|c|}
\hline Rank & Compound & \begin{tabular}{|c|} 
Number of \\
prescriptions during \\
$2000-2008$ (millions)
\end{tabular} & $\begin{array}{c}\text { FDA approval } \\
\text { year }\end{array}$ \\
\hline 1 & DICLOFENAC & 167.7 & 1993 \\
\hline 2 & METOPROLOL & 108.0 & 1978 \\
\hline 3 & IBUPROFEN & 93.8 & 1974 \\
\hline 4 & METFORMIN & 65.3 & 1995 \\
\hline 5 & BISOPROLOL & 62.8 & 1992 \\
\hline 6 & ENALAPRIL & 58.8 & 1985 \\
\hline 7 & SIMVASTATIN & 55.4 & 1991 \\
\hline 8 & FUROSEMIDE & 50.8 & 1966 \\
\hline 9 & SALBUTAMOL & 44.6 & 1981 \\
\hline 10 & RAMIPRIL & 41.7 & 1991 \\
\hline 11 & CAPTOPRIL & 40.6 & 1981 \\
\hline 12 & AMLODIPINE & 40.0 & 2009 \\
\hline 13 & VERAPAMIL & 36.4 & 1981 \\
\hline 14 & THEOPHYLLINE & 35.0 & 1970 \\
\hline 15 & GLIBENCLAMIDE & 32.5 & 1984 \\
\hline 16 & TORASEMIDE & 32.1 & 1993 \\
\hline 17 & LISINOPRIL & 29.0 & 1987 \\
\hline 18 & INSULIN HUMAN BASE/INSULIN HUMAN ISOPHANE & 28.4 & \\
\hline 19 & ISOSORBIDE DINITRATE & 28.1 & 1968 \\
\hline 20 & HYDROCHLOROTHIAZIDE & 27.3 & 1959 \\
\hline 21 & NIFEDIPINE & 26.8 & 1981 \\
\hline 22 & HYDROCHLOROTHIAZIDE/TRIAMTERENE & 24.4 & 1961.5 \\
\hline 23 & HYDROCHLOROTHIAZIDE/RAMIPRIL & 24.1 & 1975 \\
\hline 24 & NITRENDIPINE & 23.5 & \\
\hline 25 & ISOSORBIDE MONONITRATE & 22.9 & 1991 \\
\hline
\end{tabular}




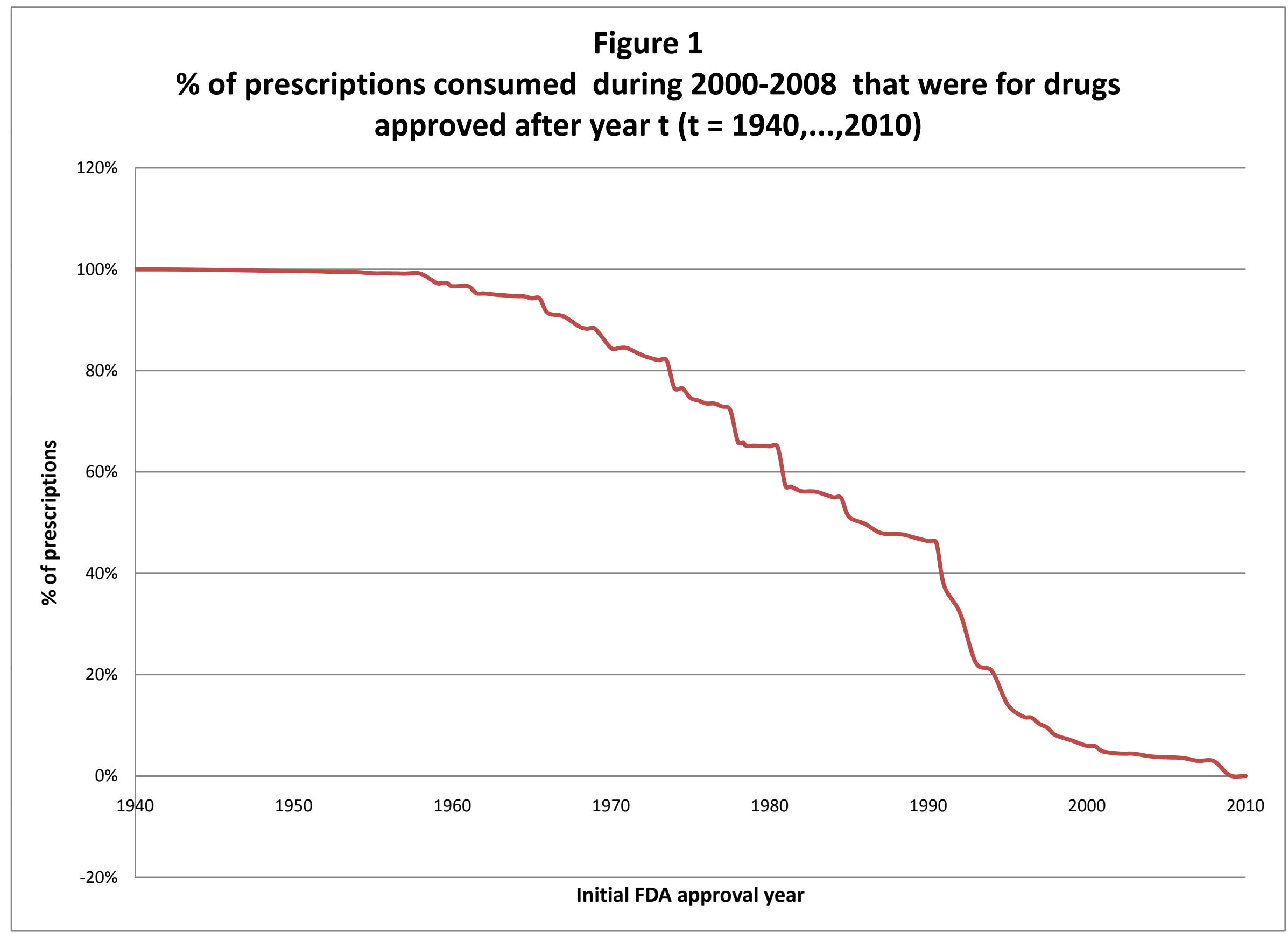


mortality rates by state and year, from which life expectancy by state and year can be calculated. $^{10}$

Data on life expectancy at birth during 2000-2007 in selected states are shown in Figure 2. The rate of increase of life expectancy varied across states and over time. In 2000, Saarland's life expectancy was higher than Mecklenburg-Vorpommern's; in 2007, it was slightly lower. In 2000, Schleswig-Holstein's life expectancy was slightly higher than Berlin's; in 2007, it was lower.

Data on other variables. Data on population, the number of notifiable diseases per 100,000 persons, ${ }^{11}$ and on the number of new AIDS cases per 100,000 persons, by state and year, were also obtained from The Information System of the Federal Health Monitoring. Data on GDP per person and the unemployment rate, by state and year, were obtained from Eurostat's regional statistics database (http://epp.eurostat.ec.europa.eu/portal/page/portal/eurostat/home). ${ }^{12}$

Summary statistics, by year, are reported in Table 2. The FDA_YEAR, POST1990\%, and POST1995\% statistics are weighted means, where the weight is the number of prescriptions. The other statistics (with the exceptions of the number of prescriptions and population) are weighted means, where the weight is the population. The mean FDA approval year increased by 3.0 years between 2000 and 2008. The fraction of prescriptions that contained ingredients approved after 1990 increased from 32\% in 2000 to $46 \%$ in 2008 . Life expectancy at birth increased by 1.8 years between 2000 and 2007 .

The complete dataset used for estimation is shown in Appendix Table 2.

\section{Empirical results}

Estimates of models of life expectancy and the age-adjusted mortality rate are presented in Table 3. We present estimates of $12(=2 \times 3 \times 2)$ different models. We use two alternative outcome measures and three alternative drug vintage measures, and estimate models both excluding and including the vector of other explanatory variables ( $\mathrm{X}$ in eq. (1)).

\footnotetext{
${ }^{10}$ We verified that population-weighted averages of our state-level life expectancy estimates were very consistent with published estimates for Germany as a whole.

${ }^{11}$ In the Federal Republic of Germany, health authorities must be informed about cases of certain notifiable diseases, which are listed in the Infection Protection Act. Depending on the disease the suspicion, the disease and/or

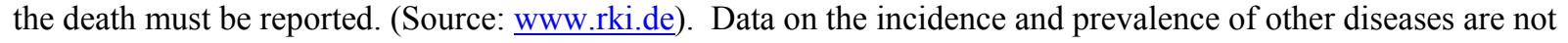
available.

${ }^{12}$ Data on educational attainment by state and year were not available.
} 


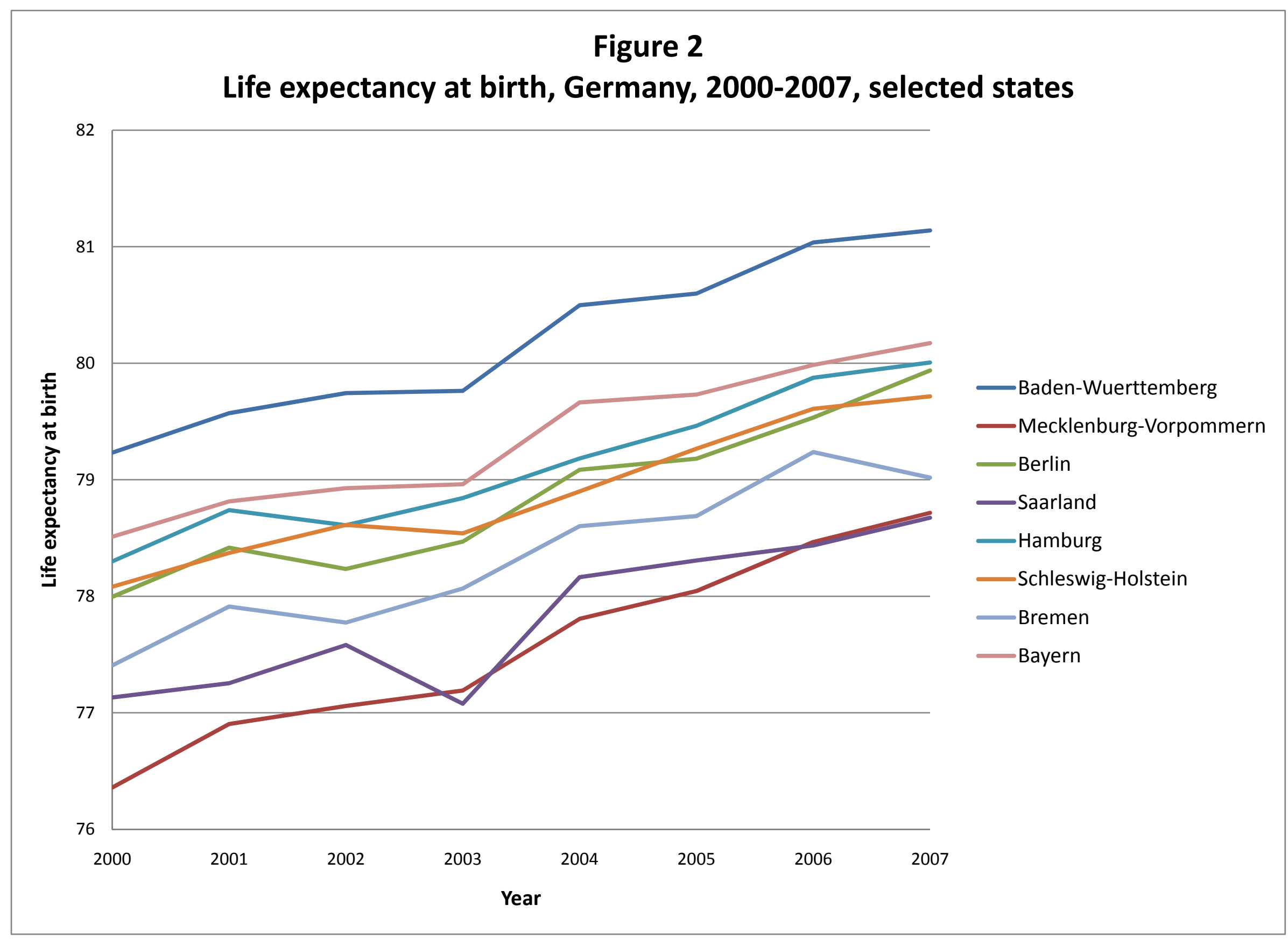


Table 2

Sample statistics by year

\begin{tabular}{|c|c|c|c|c|c|c|c|c|c|c|c|c|}
\hline ষ্ঠ & 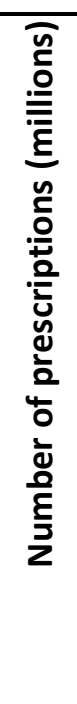 & 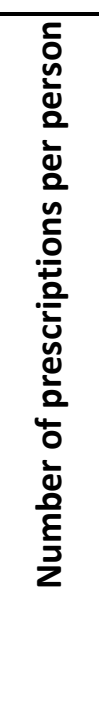 & 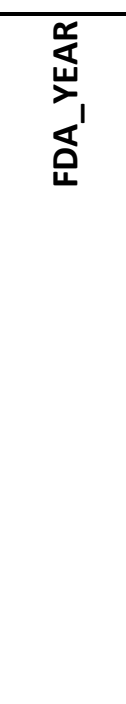 & 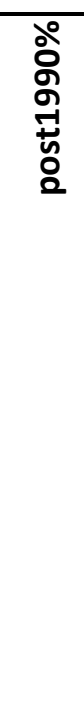 & 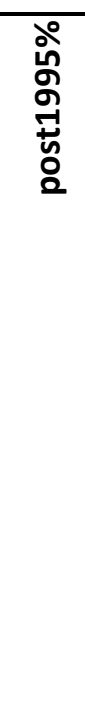 & 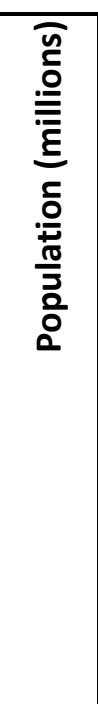 & 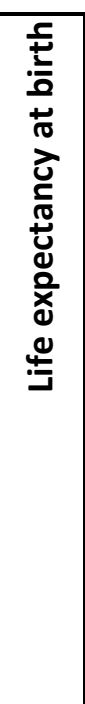 & 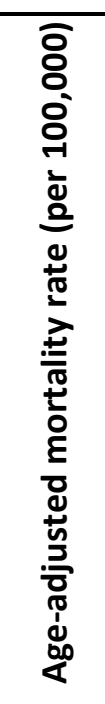 & 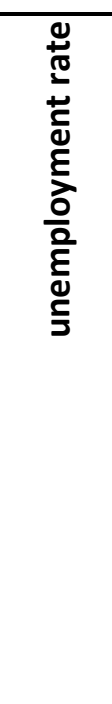 & 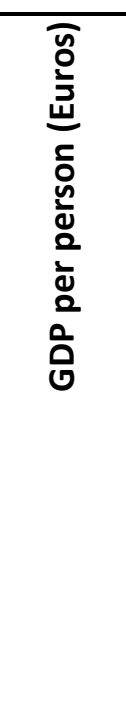 & 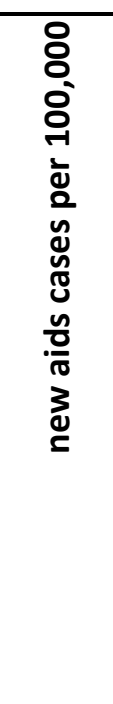 & 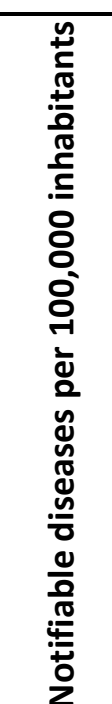 \\
\hline 2000 & 230 & 2.50 & 1983.0 & $32 \%$ & $8 \%$ & 82.2 & 78.1 & 886.0 & $7.8 \%$ & 25,095 & 1.010 & \\
\hline 2001 & 241 & 2.59 & 1983.6 & $34 \%$ & $10 \%$ & 82.3 & 78.5 & 857.4 & $7.6 \%$ & 25,664 & 0.954 & 298.4 \\
\hline 2002 & 251 & 2.71 & 1983.9 & $35 \%$ & $11 \%$ & 82.5 & 78.5 & 858.3 & $8.4 \%$ & 25,984 & 0.867 & 347.6 \\
\hline 2003 & 265 & 2.86 & 1984.3 & $37 \%$ & $12 \%$ & 82.5 & 78.6 & 861.1 & $9.7 \%$ & 26,222 & 0.844 & 308.8 \\
\hline 2004 & 235 & 2.54 & 1984.7 & $39 \%$ & $13 \%$ & 82.5 & 79.2 & 811.1 & $10.6 \%$ & 26,798 & 0.918 & 323.7 \\
\hline 2005 & 241 & 2.60 & 1984.9 & $40 \%$ & $12 \%$ & 82.5 & 79.4 & 801.0 & $11.0 \%$ &. & 0.824 & 353.7 \\
\hline 2006 & 245 & 2.64 & 1985.3 & $42 \%$ & $13 \%$ & 82.4 & 79.7 & 775.8 & $10.1 \%$ & 28,182 & 0.813 & 361.7 \\
\hline 2007 & 250 & 2.69 & 1985.6 & $44 \%$ & $14 \%$ & 82.3 & 79.9 & 766.0 & $8.6 \%$ & . & 0.733 & 541.0 \\
\hline 2008 & 259 & & 1986.0 & $46 \%$ & $15 \%$ & & & & & & & \\
\hline
\end{tabular}


Table 3

Estimates of models of life expectancy at birth and age-adjusted mortality rate, Germany, 2000-2007

\begin{tabular}{|c|c|c|c|c|c|c|c|c|c|}
\hline \multicolumn{5}{|c|}{ Dependent variable: life expectancy at birth } & \multicolumn{5}{|c|}{ Dependent variable: log of age-adjusted mortality rate } \\
\hline Model & Regressor & Estimate & Z & ProbZ & Model & Regressor & Estimate & Z & ProbZ \\
\hline & & & & & & & & & \\
\hline 1 & fda_year & 0.271 & 3.605 & 0.000 & 7 & fda_year & -0.022 & -5.094 & 0.000 \\
\hline & & & & & & & & & \\
\hline 2 & fda_year & 0.326 & 3.153 & 0.002 & 8 & fda_year & -0.031 & -4.814 & 0.000 \\
\hline 2 & Iunits_pop & -0.135 & -0.293 & 0.769 & 8 & lunits_pop & -0.021 & -0.641 & 0.521 \\
\hline 2 & unemp & -0.014 & -0.009 & 0.993 & 8 & unemp & -0.032 & -0.284 & 0.777 \\
\hline 2 & $\operatorname{lgdp}$ & -1.314 & -1.667 & 0.095 & 8 & $\operatorname{lgdp}$ & 0.125 & 1.752 & 0.080 \\
\hline 2 & laids & -0.027 & -0.565 & 0.572 & 8 & laids & 0.002 & 0.531 & 0.595 \\
\hline 2 & Inotif & -0.241 & -2.064 & 0.039 & 8 & Inotif & 0.019 & 1.975 & 0.048 \\
\hline & & & & & & & & & \\
\hline 3 & post1990 & 7.711 & 3.992 & 0.000 & 9 & post1990 & -0.646 & -4.191 & 0.000 \\
\hline & & & & & & & & & \\
\hline 4 & post1990 & 8.611 & 3.415 & 0.001 & 10 & post1990 & -0.814 & -2.820 & 0.005 \\
\hline 4 & lunits_pop & -0.115 & -0.316 & 0.752 & 10 & Iunits_pop & -0.024 & -1.162 & 0.245 \\
\hline 4 & unemp & -0.410 & -0.272 & 0.786 & 10 & unemp & 0.008 & 0.067 & 0.946 \\
\hline 4 & Igdp & -1.084 & -1.527 & 0.127 & 10 & $\operatorname{lgdp}$ & 0.101 & 1.385 & 0.166 \\
\hline 4 & laids & -0.015 & -0.323 & 0.747 & 10 & laids & 0.001 & 0.230 & 0.818 \\
\hline 4 & Inotif & -0.239 & -1.981 & 0.048 & 10 & Inotif & 0.019 & 1.812 & 0.070 \\
\hline & & & & & & & & & \\
\hline 5 & post1995 & 9.803 & 4.849 & 0.000 & 11 & post1995 & -0.821 & -6.918 & 0.000 \\
\hline & & & & & & & & & \\
\hline 6 & post1995 & 10.064 & 3.226 & 0.001 & 12 & post1995 & -0.957 & -4.896 & 0.000 \\
\hline 6 & lunits_pop & -0.206 & -0.483 & 0.629 & 12 & lunits_pop & -0.015 & -0.426 & 0.670 \\
\hline 6 & unemp & -0.021 & -0.013 & 0.990 & 12 & unemp & -0.030 & -0.254 & 0.799 \\
\hline 6 & $\operatorname{lgdp}$ & -0.925 & -1.356 & 0.175 & 12 & $\operatorname{lgdp}$ & 0.087 & 1.325 & 0.185 \\
\hline 6 & laids & -0.017 & -0.402 & 0.688 & 12 & laids & 0.001 & 0.319 & 0.750 \\
\hline 6 & Inotif & -0.154 & -1.354 & 0.176 & 12 & Inotif & 0.011 & 1.189 & 0.234 \\
\hline
\end{tabular}

The estimates are weighted least-squares estimates, weighting by state population. All equations include fixed state effects and fixed year effects. Standard errors are clustered within states. 
In model 1, the dependent variable is life expectancy at birth, and there is only one explanatory variable: the (weighted) mean FDA approval year of ingredients contained in prescriptions consumed. The coefficient on this variable is positive and highly significant (pvalue $<.001)$. This indicates that states with larger increases in drug vintage had larger increases in life expectancy. However, the estimate of this coefficient may be biased if other determinants of life expectancy are correlated with drug vintage.

Model 2 includes other plausible determinants of life expectancy: the per capita quantity of drugs consumed, per capita income, the unemployment rate, the notifiable disease rate, and the AIDS case rate. Controlling for these other variables increases the magnitude of the drug vintage coefficient by $20 \%$. The coefficients on the per capita quantity of drugs consumed, the unemployment rate, and the AIDS case rate are far from significant. The coefficient on In_NOTIF_DISEASES is negative and significant, which is to be expected: an increase in the number of notifiable diseases per 100,000 persons is associated with a decline in life expectancy.

The coefficient on per capita income is negative and nearly significant ( $\mathrm{p}$-value $=.095$ ): states with high income growth had smaller longevity increases, ceteris paribus. Some previous investigators have also found evidence of a non-monotonic or even inverse relationship between income and longevity. Uchida et al (1992) found that "for [Japanese] females high income was the factor significantly decreasing life expectancy at 65 years of age in 1980." Hupfeld (2008) theoretically derived a non-monotonic relationship between income and longevity, based on heterogeneous elasticities of labor supply and otherwise standard assumptions. He analyzed this relationship empirically for pensioners in the public pension system in Germany, and find that "the relationship between income and life expectancy is indeed non-monotonic for major subgroups in the data." And Ruhm (2004) argued that "although health is conventionally believed to deteriorate during macroeconomic downturns, the empirical evidence supporting this view is quite weak and comes from studies containing methodological shortcomings that are difficult to remedy. Recent research that better controls for many sources of omitted variables bias instead suggests that mortality decreases and physical health improves when the economy temporarily weakens. This partially reflects reductions in external sources of death, such as traffic fatalities and other accidents, but changes in lifestyles and health behaviors are also likely to play a role."

Models 3 and 4 are similar to models 1 and 2, but instead of FDA_YEAR, the measure of drug vintage is the fraction of prescriptions containing ingredients approved by the FDA after 
1990 (POST1990\%). The estimates of these two models are qualitatively similar to the estimates of models 1 and 2. The coefficient on POST1990\% is positive and highly significant, and is larger when other factors are included than it is when they are excluded.

Models 5 and 6 use the third measure of drug vintage: the fraction of prescriptions containing ingredients approved by the FDA after 1995 (POST1995\%). Once again, the drug vintage coefficient is positive and significant, and larger (albeit by a smaller margin) when other factors are controlled for. In this case, however, none of the coefficients on the other factors are close to being statistically significant.

The estimates of models 1-6 indicate that (1) there is a highly significant relationship across states between the increase in drug vintage and the increase in life expectancy, and (2) controlling for some other potentially important determinants of life expectancy, and changing the measure of drug vintage, has little effect on this relationship. Models 7-12 are similar to models 1-6, but in these models the dependent variable is the log of the age-adjusted mortality rate. The age-adjusted mortality rate and life expectancy at birth both depend on (are functions of) age-specific mortality rates, but they depend on them in different ways. The estimates of models 7-12 indicate that (1) there is a highly significant relationship across states between the increase in drug vintage and the decline in the age-adjusted mortality rate, and (2) controlling for some other potentially important determinants of the age-adjusted mortality rate, and changing the measure of drug vintage, has little effect on this relationship.

The parameter estimates can be used to estimate how much of the 1.7-year increase in life expectancy during the period 2000-2007 was attributable to the increase in drug vintage, i.e. to the use of newer drugs. These calculations are shown in the following table.

\begin{tabular}{|l|c|c|c|}
\hline Model & 2 & 4 & 6 \\
\hline Vintage measure & FDA_YEAR & post $1990 \%$ & post $1995 \%$ \\
\hline $2000-2007$ change in vintage measure $(\Delta)$ & 2.6 & $12 \%$ & $5 \%$ \\
\hline$\beta$ & 0.326 & 8.611 & 10.064 \\
\hline$\beta * \Delta$ & 0.8 & 1.0 & 0.5 \\
\hline
\end{tabular}

Model 2, based on the FDA_YEAR drug vintage measure, implies that use of newer drugs increased life expectancy at birth by 0.8 years (almost half of the actual increase in life expectancy) during the period 2000-2007. Model 4, based on the POST1990\% drug vintage measure, implies that use of newer drugs increased life expectancy by a larger amount: 1.0 years. 
Model 6, based on the POST1995\% drug vintage measure, implies that use of newer drugs increased life expectancy by a smaller amount: 0.5 years. The mean of these three estimates is 0.8 years.

The parameter estimates can also be used to obtain a rough assessment of the overall cost-effectiveness of pharmaceutical innovation. We define the incremental cost-effectiveness ratio (ICER) as follows:

ICER $=\underline{\text { change in lifetime drug expenditure due to pharmaceutical innovation }}$ change in life expectancy due to pharmaceutical innovation

The underlying calculations are shown in the following table.

\begin{tabular}{|l|c|c|c|}
\hline Year & $\begin{array}{c}\text { Life } \\
\text { expectancy }\end{array}$ & $\begin{array}{c}\text { annual drug expenditure } \\
\text { in constant } 2000 €^{1}\end{array}$ & $\begin{array}{c}\text { lifetime drug expenditure (= life } \\
\text { expectancy * annual drug } \\
\text { expenditure) }\end{array}$ \\
\hline 2000 & 78.1 & $€ 300$ & $€ 23,430$ \\
\hline 2006 & $78.8^{2}$ & $€ 364$ & $€ 28,683$ \\
\hline change & 0.7 & & $€ 5,253$ \\
\hline
\end{tabular}

1: Source: 2009 OECD Health Database

2: "Predicted" life expectancy in $2006=\mathrm{LE}_{2000}+\beta\left(\mathrm{VINT}_{2006}-\mathrm{VINT}_{2000}\right)$

German life expectancy at birth was 78.1 years in 2000. The mean of the estimates of $\beta$ from models 2, 4, and 6 implies that the increase in drug vintage increased life expectancy by 0.7 years between 2000 and 2006. According to the 2009 OECD Health Database, per capita expenditure (in constant $2000 €$ ) on prescription drugs increased from $€ 300$ in 2000 to $€ 364$ in 2006. Assuming that this increase was entirely due to use of newer drugs, pharmaceutical innovation increased lifetime drug expenditure by $€ 5,253$. The implied ICER is $€ 7512$ (=€ 5,253 / 0.70 years) per life-year. This is a small fraction of leading economists' estimates of the value of (willingness to pay for) an additional year of life. Moreover, while use of newer drugs undoubtedly increases pharmaceutical expenditure, there is evidence that it reduces other medical expenditure (especially hospital expenditure (Lichtenberg (2009)), so the true ICER may be lower than $€ 7512$. 


\section{French cancer mortality}

Now I will investigate the effect of the vintage of chemotherapy treatments on mortality rates of French cancer patients, using longitudinal, annual, cancer-site (breast, colon, lung, etc.) level data during the period 2002-2006.

Two types of statistics are used to measure cancer mortality: survival rates and mortality rates. Survival rates are typically expressed as the proportion of patients alive at some point subsequent to the diagnosis of their cancer. For example, the observed 5-year survival rate is defined as follows:

5-year Survival Rate $=$ Number of people diagnosed with cancer at time $t$ alive at time $t+5$ / Number of people diagnosed with cancer at time $t$

$=1-($ Number of people diagnosed with cancer at time $t$ dead at time $t+5 /$ Number of people diagnosed with cancer at time $\mathrm{t}$ )

Hence, the survival rate is based on a conditional (upon previous diagnosis) mortality rate. The second type of statistic is the unconditional cancer mortality rate: the number of deaths, with cancer as the underlying cause of death, occurring during a year per 100,000 population.

The outcome measure I will analyze is the unconditional (age-adjusted) cancer mortality rate. Longitudinal, cancer-site level data on conditional mortality (or survival) are not available during the period for which we have chemotherapy treatment data (2002-2006), although they are available for earlier years. ${ }^{13}$ Moreover, Welch et al (2000) argued that "while 5-year survival is a perfectly valid measure to compare cancer therapies in a randomized trial, comparisons of 5year survival rates across time (or place) may be extremely misleading. If cancer patients in the past always had palpable tumors at the time of diagnosis while current cancer patients include those diagnosed with microscopic abnormalities, then 5-year survival would be expected to increase over time even if new screening and treatment strategies are ineffective." Consequently, Welch et al (2000) concluded that "to avoid the problems introduced by changing patterns of diagnosis...progress against cancer [should] be assessed using [unconditional] population-based mortality rates."

\footnotetext{
${ }^{13}$ The Eurocare 3 and Eurocare 4 databases (http://www.eurocare.it/Home/tabid/36/Default.aspx) provide data on survival rates of French cancer patients diagnosed during the following periods: 1983-1985, 1986-1988, 1989-1991, 1992-1994, and 1995-1999.
} 


\section{A. Econometric model}

I will estimate models of the following form:

$\ln (\mathrm{AAMORT})_{\mathrm{st}}=\beta \mathrm{VINTAGE}_{\mathrm{st}}+\alpha_{\mathrm{s}}+\delta_{\mathrm{t}}+\varepsilon_{\mathrm{st}}$

where

$\ln \left(\mathrm{AAMORT}_{\mathrm{st}}\right)=$ the $\log$ of the age-adjusted mortality rate from cancer at site $\mathrm{s}$ in year $\mathrm{t}(\mathrm{s}=1, \ldots, 24 ; \mathrm{t}=20002, \ldots, 2006)$

VINTAGE is one of the following variables:

$\mathrm{LAUNCH}_{-} \mathrm{YEAR}_{\mathrm{st}}=$ the (weighted) mean world launch year of chemotherapy treatments for cancer site $\mathrm{s}$ in year $\mathrm{t}$

POST $1985 \%_{\mathrm{st}}=$ the percent of chemotherapy treatments for cancer site $\mathrm{s}$ in year $\mathrm{t}$ that contained ingredients launched after 1985

POST $1990 \% \%_{\text {st }}=$ the percent of chemotherapy treatments for cancer site $\mathrm{s}$ in year $\mathrm{t}$ that contained ingredients launched after 1990

$\alpha_{\mathrm{s}}$ and $\delta_{\mathrm{t}}$ represent cancer-site fixed effects and year fixed effects, respectively. A significant negative drug vintage coefficient $(\beta)$ in eq. (2) would indicate that cancer sites that had aboveaverage increases in drug vintage had above-average reductions in the age-adjusted mortality rate.

Eq. (2) will be estimated by weighted least squares, weighting by the mean of each cancer site's mortality rate during the entire sample period $\left((1 / \mathrm{T}) \sum_{\mathrm{t}} \mathrm{AAMORT}_{\mathrm{st}}\right)$. The estimation procedure will account for clustering of disturbances within cancer sites.

The drug vintage measure LAUNCH_YEAR will be constructed as follows:

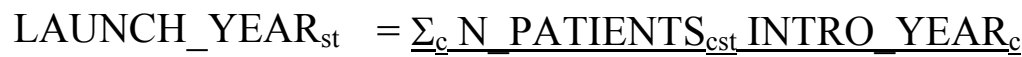

$$
\begin{aligned}
& \Sigma_{\mathrm{c}} \mathrm{N}_{-} \text {PATIENTS } \mathrm{cst}
\end{aligned}
$$

where

N_PATIENTS cst $=$ the number of patients with cancer at site s who were treated with chemotherapy agent $\mathrm{c}$ in year $\mathrm{t}$

INTRO_YEAR I $_{\mathrm{c}}=$ the year in which chemotherapy agent $\mathrm{c}$ was first launched

The drug vintage measure POST1985\% will be constructed as follows: 


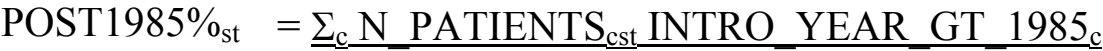 $\Sigma_{\mathrm{c}} \mathrm{N}_{-}$PATIENTS $\mathrm{cst}$}

where

INTRO_YEAR_GT_1985 $=1$ if chemotherapy agent c was first launched after 1985

$$
=0 \text { otherwise }
$$

POST1990\% will be constructed in a similar fashion.

The only explanatory variable in eq. (2) (aside from the cancer-site fixed effects and year fixed effects) is chemotherapy vintage. Cancer mortality rates are also likely to depend on other cancer-site-specific, time-varying variables, and these might be correlated with drug vintage. In particular, mortality rates are likely to depend on (1) incidence rates, and (2) non-pharmaceutical innovation. Unfortunately, data on cancer incidence and non-pharmaceutical innovation, by cancer site, are not available for France during the period covered by our chemotherapy data. ${ }^{14}$ However, in a recent paper based on U.S. cancer data during the period 1996-2006, Lichtenberg (2010) found that, although pharmaceutical innovation, non-pharmaceutical innovation, and incidence all had significant effects on cancer mortality rates, controlling for the latter two variables had virtually no effect on the pharmaceutical innovation coefficient.

\section{B. Data and descriptive statistics}

Pharmaceutical data. Data on the number of patients with cancer at site s who were treated with chemotherapy agent $\mathrm{c}$ in year $\mathrm{t}\left(\mathrm{N} \_\right.$PATIENTS $\left.{ }_{\mathrm{cst}}\right)$ were obtained from IMS Health's Oncology Analyzer database. ${ }^{15}$ IMS collected data on the frequency with which 11 chemotherapy agents were administered to a sample of about 20,000 French cancer patients during the period 20022006. As the following table shows, the size of the sample increased over time:

\begin{tabular}{|c|c|}
\hline Year & Number of sample patients \\
\hline 2002 & 2713 \\
\hline 2003 & 3195 \\
\hline 2004 & 3767 \\
\hline 2005 & 5063 \\
\hline 2006 & 5217 \\
\hline
\end{tabular}

\footnotetext{
${ }^{14}$ Data on non-pharmaceutical innovation are not available for any period. According to the European Cancer Observatory, annual data on cancer incidence, by site, are only available during the period 1983-1997 (http://eucancer.iarc.fr/16-table.html,en).

${ }^{15}$ If a patient was treated with $\mathrm{n}$ chemotherapy agents, that patient would be counted $\mathrm{n}$ times.
} 
The eleven drugs (ranked by frequency of use), and the years in which they were launched, are shown in the following table:

\begin{tabular}{|l|l|c|}
\hline frequency rank & chemotherapy agent & world launch year \\
\hline 1 & doxorubicin & 1971 \\
\hline 2 & epirubicin & 1984 \\
\hline 3 & gemcitabine & 1995 \\
\hline 4 & carboplatin & 1985 \\
\hline 5 & docetaxel & 1995 \\
\hline 6 & paclitaxel & 1992 \\
\hline 7 & vinorelbine & 1989 \\
\hline 8 & imatinib & 2001 \\
\hline 9 & capecitabine & 1998 \\
\hline 10 & temozolomide & 1999 \\
\hline 11 & pemetrexed & 2004 \\
\hline
\end{tabular}

Table 4 shows the number of sample patients during 2002-2006, by cancer site. The two cancer sites with the largest number of patients were breast and lung. The three chemotherapy agents most frequently used to treat each of the five cancer sites with the largest numbers of patients are shown in Table $5 .{ }^{16}$

Mortality data. Data on age-adjusted ${ }^{17}$ mortality rates, by cancer site, were obtained from the Centre d'épidémiologie sur les causes médicales de décès, Institut national de la santé et de la recherche médicale (http://www.cepidc.vesinet.inserm.fr/inserm/html/index2.htm).

The complete dataset used for estimation is shown in Appendix Table 3.

\section{Empirical results}

Estimates of chemotherapy vintage coefficients $(\beta)$ from different versions of eq. (2) are shown in Table 6. The first three estimates are based on the full set of cancer sites. In model 1, the vintage measure is the (weighted) mean world launch year of chemotherapy treatments. The coefficient on LAUNCH_YEAR is negative and highly significant ( $p$-value $=.008)$. This indicates that cancer sites for which there were larger increases in chemotherapy vintage had larger reductions in the age-adjusted mortality rate. A 10-year increase in mean drug vintage is estimated to reduce the age-adjusted mortality rate by about $6 \%$. Models 2 and 3 indicate that

\footnotetext{
${ }^{16}$ Only two drugs were used to treat Hodgkin's disease among sample patients.

17 The age distribution of the French population in 2002 was used to obtain age-adjusted mortality rates.
} 
Table 4

Number of sample patients during 2002-2006, by cancer site

\begin{tabular}{|l|r|}
\hline Cancer site & Number of sample patients, 2002-2006 \\
\hline BREAST & 5027 \\
\hline LUNG & 4270 \\
\hline NHL & 2245 \\
\hline OVARIAN & 1534 \\
\hline HODGKINS DISEASE & 834 \\
\hline PANCREAS & 819 \\
\hline CML & 648 \\
\hline BRAIN & 461 \\
\hline M.MYELOMA \& MALIG PLASMA CELL & 401 \\
\hline HEAD \& NECK & 379 \\
\hline COLORECTAL & 332 \\
\hline BLADDER & 277 \\
\hline PROSTATE & 246 \\
\hline LIVER & 243 \\
\hline STOMACH & 152 \\
\hline CLL & 146 \\
\hline CORPUS UTERI & 94 \\
\hline OESOPHAGUS & 77 \\
\hline ALL & 59 \\
\hline MELANOMA & 26 \\
\hline KIDNEY & 20 \\
\hline OTHER LEUKAEMIAS & 9 \\
\hline AML & 4 \\
\hline THYROID & 4 \\
\hline CERVIX UTERI & 2 \\
\hline MYELOID LEUKAEMIA OTHER/UNSPEC & 1 \\
\hline OTHER & 1645 \\
\hline
\end{tabular}

Source: IMS Oncology Analyzer 
Table 5

Chemotherapy agents most frequently used to treat French cancer patients during 2002-2006,

by cancer site

\begin{tabular}{|c|c|}
\hline Chemotherapy agent & Rank \\
\hline \multicolumn{2}{|c|}{ BREAST } \\
\hline EPIRUBICIN & 1 \\
\hline DOCETAXEL & 2 \\
\hline DOXORUBICIN & 3 \\
\hline \multicolumn{2}{|c|}{ LUNG } \\
\hline VINORELBINE & 1 \\
\hline GEMCITABINE & 2 \\
\hline CARBOPLATIN & 3 \\
\hline \multicolumn{2}{|c|}{$\mathrm{NHL}$} \\
\hline DOXORUBICIN & 1 \\
\hline EPIRUBICIN & 2 \\
\hline TEMOZOLOMIDE & 3 \\
\hline \multicolumn{2}{|c|}{ OVARIAN } \\
\hline CARBOPLATIN & 1 \\
\hline PACLITAXEL & 2 \\
\hline GEMCITABINE & 3 \\
\hline \multicolumn{2}{|c|}{ HODGKINS DISEASE } \\
\hline DOXORUBICIN & 1 \\
\hline VINORELBINE & 2 \\
\hline
\end{tabular}

Source: IMS Oncology Analyzer 
Table 6

Estimates of models of age-adjusted cancer mortality rate, France, 2002-2006

\begin{tabular}{|c|c|c|c|c|c|c|c|}
\hline Model & Regressor & Estimate & Stderr & LowerCL & UpperCL & Z & ProbZ \\
\hline & \multicolumn{7}{|c|}{ All cancer sites } \\
\hline 1 & Launch_Year & -0.006 & 0.002 & -0.011 & -0.002 & -2.665 & 0.008 \\
\hline 2 & post $1985 \%$ & -0.122 & 0.034 & -0.187 & -0.056 & -3.618 & 0.000 \\
\hline & & & & & & & \\
\hline \multirow[t]{2}{*}{3} & post1990\% & -0.107 & 0.029 & -0.165 & -0.049 & -3.644 & 0.000 \\
\hline & \multicolumn{7}{|c|}{ Excluding lung cancer } \\
\hline 4 & Launch Year & -0.008 & 0.002 & -0.011 & -0.005 & -5.035 & 0.000 \\
\hline 5 & post1985\% & -0.094 & 0.028 & -0.150 & -0.039 & -3328 & 0.001 \\
\hline & & & & & & & \\
\hline 6 & post $1990 \%$ & -0.131 & 0.019 & -0.168 & -0.094 & -6.936 & 0.000 \\
\hline
\end{tabular}

The estimates are weighted least-squares estimates, weighting by the mean of each cancer site's mortality rate during the entire sample period $\left((1 / T) \Sigma_{t} A A M O R T_{s t}\right)$. All equations include fixed cancer-site effects and fixed year effects. Standard errors are clustered within cancer sites. 
the change in the age-adjusted mortality rate was also inversely correlated with the other two measures of chemotherapy vintage (POST1985\% and POST1990\%). Model 2 implies that the mortality rate would be about $12 \%$ lower if only post-1985 drugs were used than it would be if only pre-1986 drugs were used.

As noted earlier, these are weighted least-squares estimates, where the weight is the mean of each cancer site's mortality rate during the entire sample period. As shown in Figure 3, the mortality rate for lung cancer is far higher than it is for other types of cancer. Therefore, the estimates of models 1-3 give a great deal of weight to the lung cancer data. Models 4-6 are estimates based on the full set of cancer sites except lung cancer. All three drug vintage coefficients remain negative and highly significant when lung cancer is excluded from the sample. Excluding lung cancer increases the magnitude of $\beta$ by about $25 \%$ in models 4 and 6 , but reduces the magnitude of $\beta$ by about $25 \%$ in model 5 .

According to Eurostat, ${ }^{18}$ the age-adjusted mortality rate from malignant neoplasms in France declined by $6 \%$ between 2002 and 2006. The parameter estimates can be used to estimate how much of this decline was attributable to the increase in drug vintage, i.e. to the use of newer chemotherapy agents. The decline in the age-adjusted mortality rate attributable to the 2002-2006 increase in drug vintage is $\beta * \Delta$, where $\Delta=\left(\mathrm{V}_{2006}-\mathrm{V}_{2002}\right)$ and $\mathrm{V}_{\mathrm{t}}=$ mean drug vintage in year $\mathrm{t}$.

There are two different data sources from which we can calculate $\Delta$. The first is the IMS Oncology Analyzer database. As noted above, this contains data on the use of 11 cancer drugs by about 4000 patients per year during the period 2002-2006. The second data source is the Groupement pour 1 'Elaboration et la Réalisation de Statistiques (GERS, http://www.giegers.fr/index.php3). This source provides annual data on the use of all (106) cancer drugs by all cancer patients in France during the period 1998-2007. ${ }^{19}$

Table 7 shows a comparison of chemotherapy vintage measures derived from the IMS Oncology Analyzer and GERS databases. ${ }^{20}$ The GERS estimates of the 2002-2006 increase in mean vintage are about three times as large as the IMS estimates. For example, the GERS data

\footnotetext{
${ }^{18}$ Source: Eurostat hlth_cd_asdr dataset.

${ }^{19}$ GERS provides data on the quantity of each drug, by year, but not by cancer site.

${ }^{20}$ The GERS vintage measures are based on the year each drug was first commercialized in France, rather than the world launch year, which is not available for all drugs. For the 11 drugs for which both dates were available, there is generally a close correspondence between the two dates. For 8 out of the 11 drugs, the year of commercialization in France was 0-2 years after the world launch year.
} 
Figure 3

Number of deaths per 100,000 population, by cancer site, France, 2006

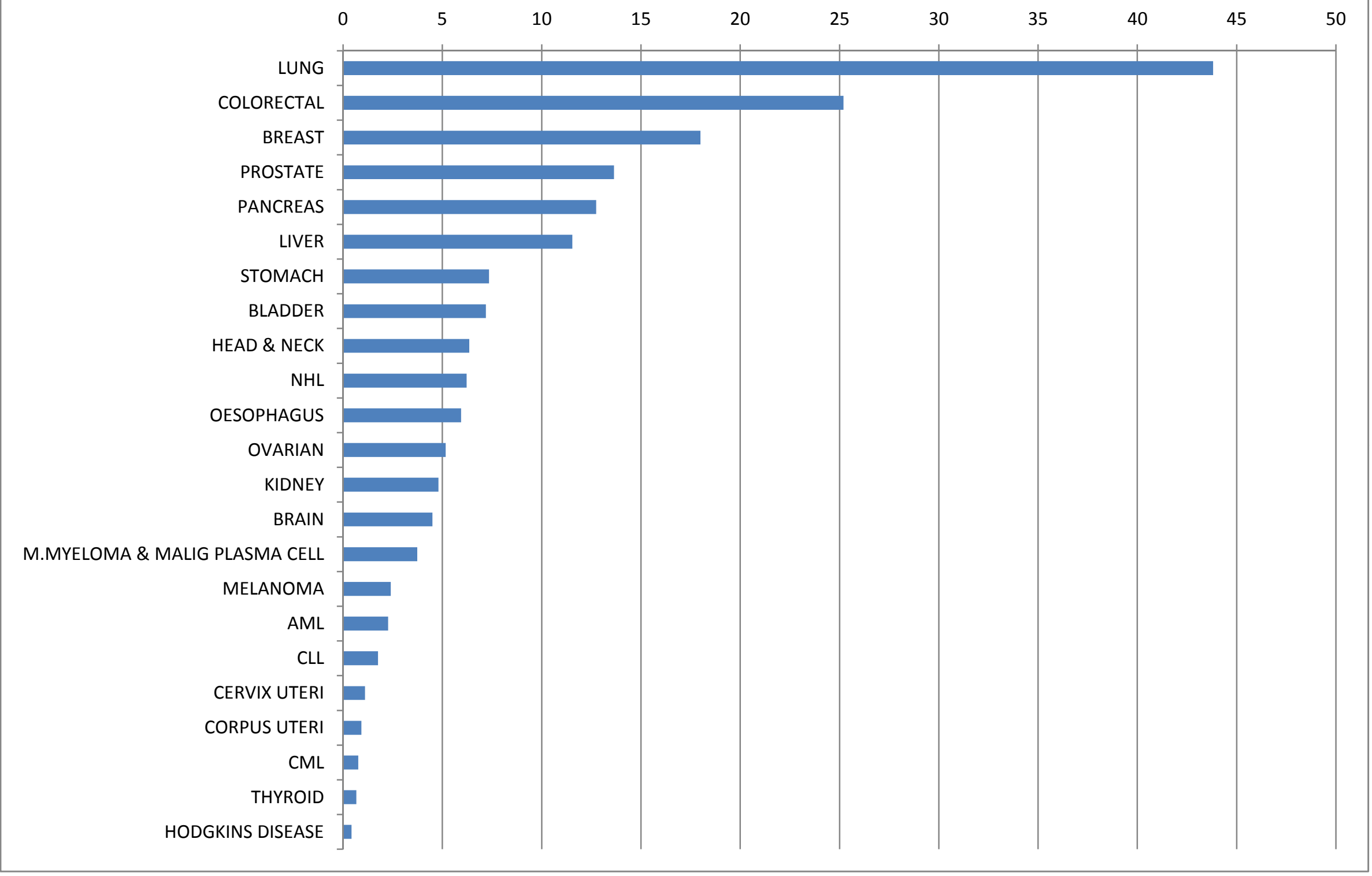


Table 7

Comparison of chemotherapy vintage measures derived from IMS Oncology Analyzer and GERS databases

\begin{tabular}{|l|c|c|c|c|c|c|c|c|}
\hline year & \multicolumn{2}{|c|}{$\mathrm{N}$} & \multicolumn{2}{c|}{ LAUNCH_YEAR } & \multicolumn{2}{c|}{ POST1985\% } & \multicolumn{2}{c|}{ POST1990\% } \\
\hline & IMS & GERS & IMS & GERS & IMS & GERS & IMS & GERS \\
\hline 1998 & & $109,507,687$ & & 1978.3 & & $30 \%$ & & $10 \%$ \\
\hline 1999 & & $111,235,927$ & & 1978.9 & & $32 \%$ & & $15 \%$ \\
\hline 2000 & & $115,983,400$ & & 1979.6 & & $35 \%$ & & $19 \%$ \\
\hline 2001 & & $124,227,347$ & & 1980.7 & & $38 \%$ & & $25 \%$ \\
\hline 2002 & 2713 & $138,344,711$ & 1985.6 & 1982.1 & $47 \%$ & $44 \%$ & $37 \%$ & $32 \%$ \\
\hline 2003 & 3195 & $150,057,851$ & 1986.2 & 1984.0 & $50 \%$ & $53 \%$ & $39 \%$ & $41 \%$ \\
\hline 2004 & 3767 & $156,556,767$ & 1986.3 & 1985.7 & $49 \%$ & $60 \%$ & $43 \%$ & $49 \%$ \\
\hline 2005 & 5063 & $157,138,449$ & 1987.3 & 1986.8 & $53 \%$ & $64 \%$ & $46 \%$ & $57 \%$ \\
\hline 2006 & 5217 & $167,624,451$ & 1987.4 & 1987.6 & $53 \%$ & $67 \%$ & $46 \%$ & $61 \%$ \\
\hline 2007 & & $175,757,939$ & & 1988.1 & & $69 \%$ & & $63 \%$ \\
\hline & & & & & & & & \\
\hline $2006-2002$ & & & 1.8 & 5.5 & $7 \%$ & $23 \%$ & $9 \%$ & $29 \%$ \\
\hline
\end{tabular}


imply that mean LAUNCH_YEAR increased by 5.5 years, while the IMS data imply that it increased by only 1.8 years.

Estimates of the decline in the age-adjusted mortality rate attributable to the 2002-2006 increase in drug vintage based on both the IMS data and the GERS data are shown in the following table.

\begin{tabular}{|l|c|c|c|}
\hline Model & 1 & 2 & 3 \\
\hline Vintage measure & LAUNCH_YEAR & POST1985\% & POST1990\% \\
\hline$\beta$ & -0.006 & -0.122 & -0.107 \\
\hline & \multicolumn{3}{|c|}{ GERS database } \\
\hline $2002-2006$ change in vintage measure $(\Delta)$ & 1.8 & 7 IMS Oncology Analyzer database \\
\hline$\beta * \Delta$ & -0.011 & -0.008 & -0.010 \\
\hline & 5.5 & $23 \%$ & $29 \%$ \\
\hline & -0.034 & -0.028 & -0.031 \\
\hline $2002-2006$ change in vintage measure $(\Delta)$ & \multicolumn{3}{|c|}{$7 \%$} \\
\hline$\beta * \Delta$ & &
\end{tabular}

The estimates of $\Delta$ derived from the IMS database imply that the increase in drug vintage reduced the age-adjusted cancer mortality rate by about $1 \%$ during 2002-2006, which is about $1 / 6$ of the total decline in the mortality rate. The estimates of $\Delta$ derived from the GERS database imply that the increase in drug vintage reduced the age-adjusted cancer mortality rate by about $3 \%$ during 2002-2006, which is about half of the total decline in the mortality rate.

\section{Summary}

Longevity increase is an important part of economic growth and development. In the long run, the rate of economic growth is determined by the rate of technological progress, which is generated by private and public $R \& D$ investment. Most technological progress is embodied in new goods. Therefore, the welfare of consumers (and the productivity of producers) depends on the vintage of the goods (or inputs) they purchase, especially when those goods are R\&Dintensive. The pharmaceutical and medical devices industries are the most R\&D-intensive industries in the economy

In this paper, I have investigated the contribution of pharmaceutical innovation to recent longevity growth in Germany and France. First, I examined the effect of the vintage of 
prescription drugs (and other variables) on the life expectancy and age-adjusted mortality rates of residents of Germany, using longitudinal, annual, state-level data during the period 2000-2007. Then, I examined the effect of the vintage of chemotherapy treatments on age-adjusted cancer mortality rates of residents of France, using longitudinal, annual, cancer-site-level data during the period 2002-2006.

The analysis of Germany was based on data on the utilization of over 600 active ingredients, which account for about 250 million prescriptions per year. I found that states with larger increases in drug vintage had larger increases in life expectancy. Controlling for some other potentially important determinants of life expectancy (the per capita quantity of drugs consumed, per capita income, the unemployment rate, the notifiable disease rate, and the AIDS case rate) and changing the measure of drug vintage, had little effect on the relationship between drug vintage and life expectancy. There was also a highly significant relationship across states between the increase in drug vintage and the decline in the age-adjusted mortality rate.

German life expectancy at birth increased by 1.7 years during the period 2000-2007. The estimates imply that almost half of this increase was due to the replacement of older drugs by newer drugs. My estimate of the cost per life-year gained from the use of newer drugs is a small fraction of leading economists' estimates of the value of (willingness to pay for) an additional year of life.

The analysis of France was based on data on the utilization of 11 cancer drugs by about 4000 cancer patients per year. I found that cancer sites for which there were larger increases in chemotherapy vintage had larger reductions in the age-adjusted mortality rate. A 10-year increase in mean drug vintage was estimated to reduce the age-adjusted mortality rate by about $6 \%$. Changing the measure of drug vintage, and excluding lung cancer-by far the largest cause of cancer deaths in France- - had little effect on the relationship between drug vintage and the cancer mortality rate. My estimates implied that chemotherapy innovation accounted for at least one-sixth of the decline in French cancer mortality rates during 2002-2006, and may have accounted for as much as half of the decline. 


\section{References}

Bahk, Byong-Hyong and Michael Gort (1993), "Decomposing Learning by Doing in New Plants," Journal of Political Economy, 101, 561-583.

Bils, Mark (2004), "Measuring the Growth from Better and Better Goods," NBER working paper no. 10606, July, http://www.nber.org/papers/w10606.

Bresnahan, Timothy F., and Robert J. Gordon (1996), The Economics of New Goods (Chicago: University of Chicago Press).

Grossman, Gene M., and Elhanan Helpman (1993), Innovation and Growth in the Global Economy (Cambridge: MIT Press).

Hulten, Charles R. (1992), "Growth accounting when technical change is embodied in capital," The American Economic Review, Vol. 82, No. 4. (Sep., 1992), pp. 964-980.

Hupfeld, Stefan (2008), "Non-Monotonicity in the Longevity-Income-Relationship," working paper, Department of Economics, University of Konstanz, Germany, August 14, http://wipol.wiwi.uni-konstanz.de/lehrstuhl/personen/hupfeld non monotinicity.pdf

Jones, Charles (1998), Introduction to Economic Growth (New York: Norton).

Lichtenberg, Frank (2009), "Have newer cardiovascular drugs reduced hospitalization? Evidence from longitudinal country-level data on 20 OECD countries, 1995-2003," Health Economics 18 (5), 519-534.

Lichtenberg, Frank (2010), "Has medical innovation reduced cancer mortality?," NBER Working Paper 15880, April, http://www.nber.org/papers/w15880

Murphy, Kevin M. and Topel, Robert H. (2005), “The Value of Health and Longevity," NBER Working Paper No. W11405. (June). Available at SSRN: http://ssrn.com/abstract=742364

National Science Foundation, U.S. Corporate R\&D: Volume 1: Top 500 Firms in R\&D by Industry Category, http://www.nsf.gov/statistics/nsf00301/expendit.htm.

Nordhaus, William D. (2002), "The Health of Nations: The Contribution of Improved Health to Living Standards" (March). NBER Working Paper No. W8818. Available at SSRN:

http://ssrn.com/abstract $=302579$

Romer, Paul (1990), "Endogenous Technological Change," Journal of Political Economy, October.

Ruhm, Christopher J. (2004), "Macroeconomic Conditions, Health and Mortality," NBER Working Paper No. W11007, December, http://www.nber.org/papers/w11007 
Sakellaris, Plutarchos and Dan Wilson (2004), "Quantifying Embodied Technological Change," Review of Economic Dynamics 7(1), pp. 1-26.

Solow, Robert M. (1956). "A Contribution to the Theory of Economic Growth". Quarterly Journal of Economics 70 (1): 65-94.

Solow, Robert M. (1957). "Technical Change and the Aggregate Production Function". Review of Economics and Statistics 3 (3): 312-320.

Solow, Robert M. (1960), "Investment and technological progress," in K. Arrow, S. Karlin and P. Suppes (eds.), Mathematical Methods in Social Sciences 1959, 89.104. Stanford University Press.

Uchida, Eiichi, Shunichi Araki and Katsuyuki Murata (1992), "Socioeconomic factors affecting the longevity of the Japanese population: a study for 1980 and 1985," Journal of Biosocial Science 24, 497-504.

Welch, H. Gilbert, Lisa M. Schwartz, and Steven Woloshin (2000), “Are Increasing 5-Year Survival Rates Evidence of Success Against Cancer?,” JAMA 283 (22). 2975-2978 http://jama.ama-assn.org/cgi/content/abstract/283/22/2975?ck=nck

Wikipedia, Human Development Index, http://en.wikipedia.org/wiki/Human_Development_Index 
Appendix Table 1

Sample coverage of drugs in 2008

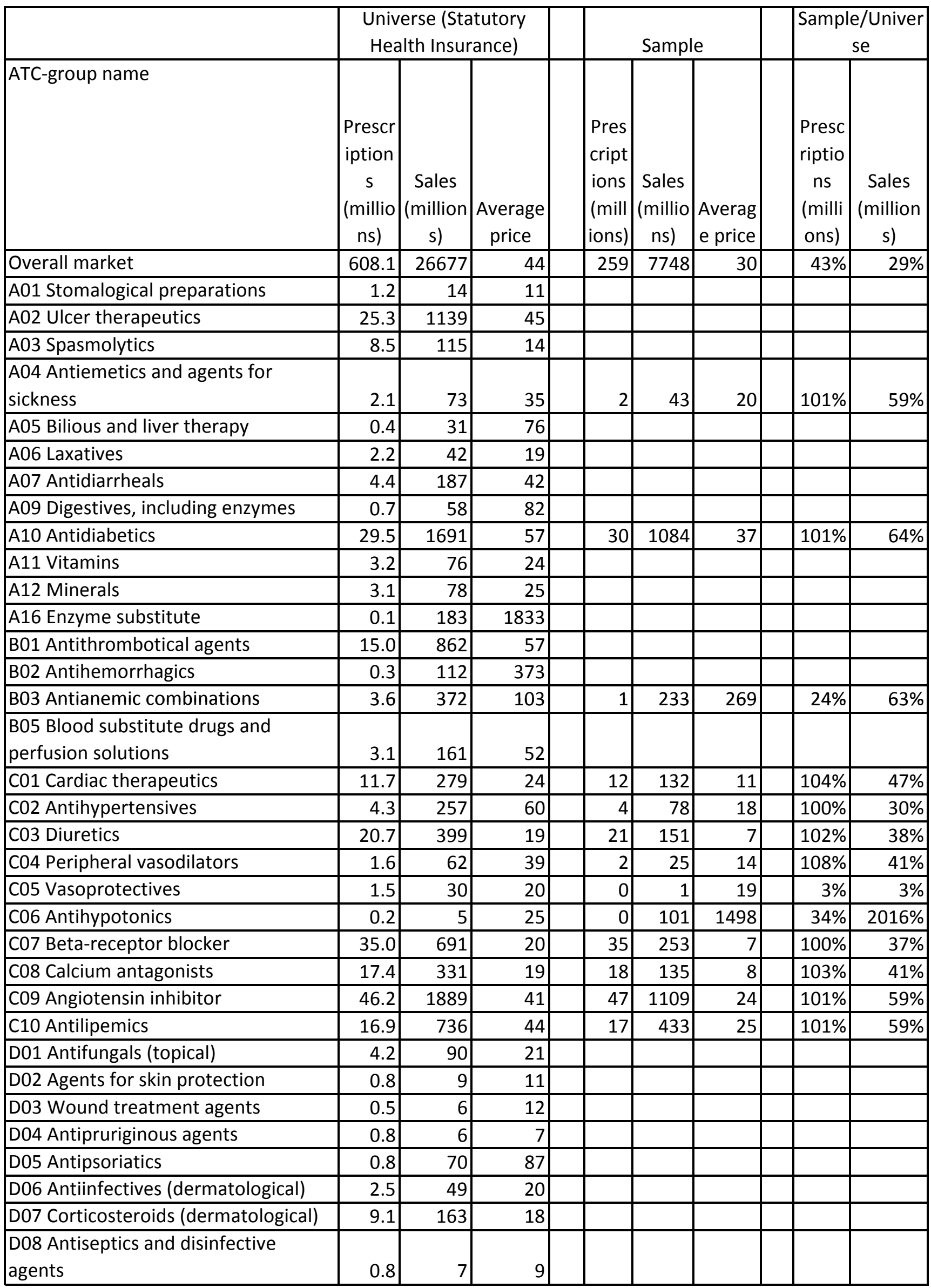


Appendix Table 1

Sample coverage of drugs in 2008

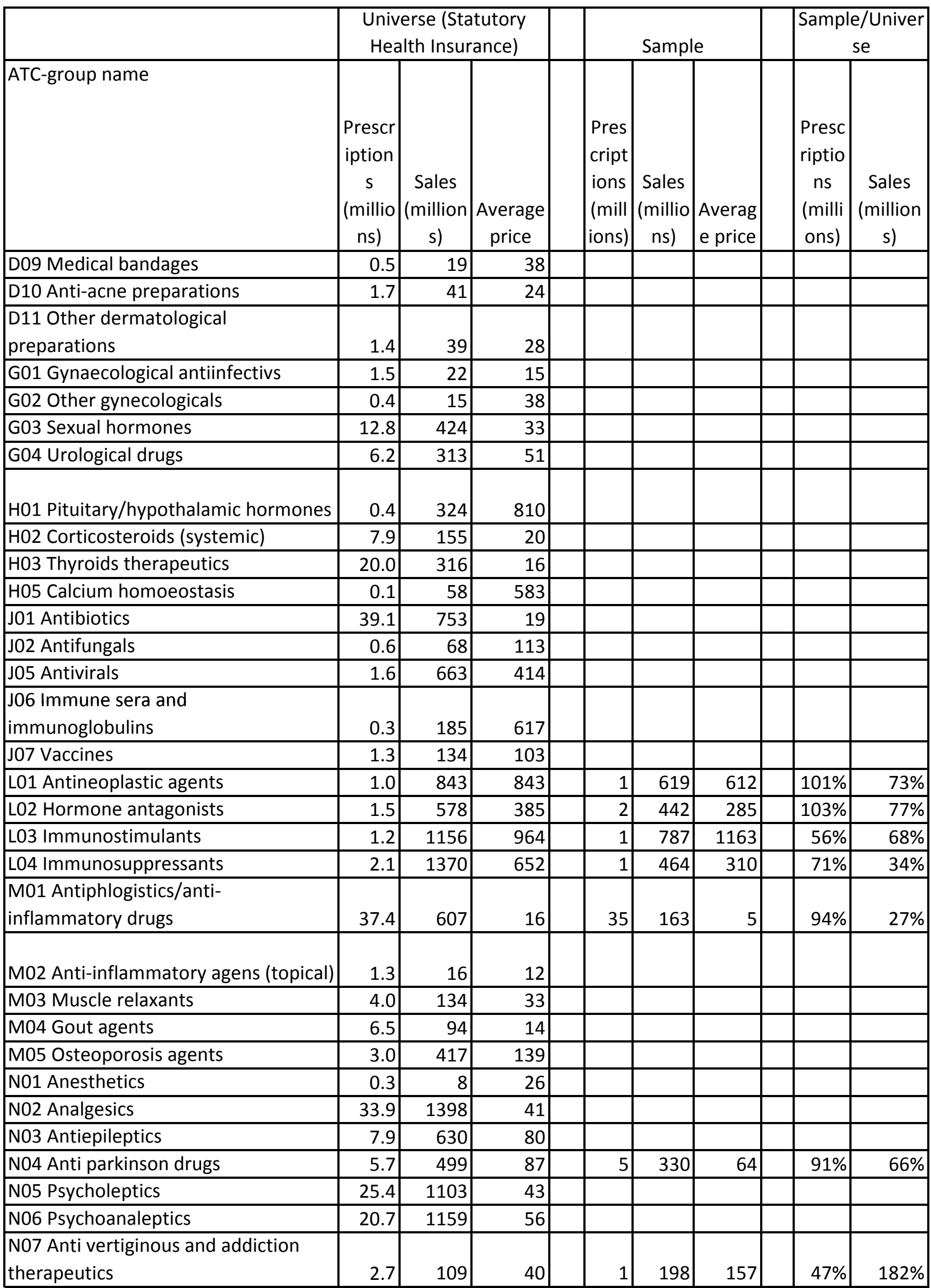


Sample coverage of drugs in 2008

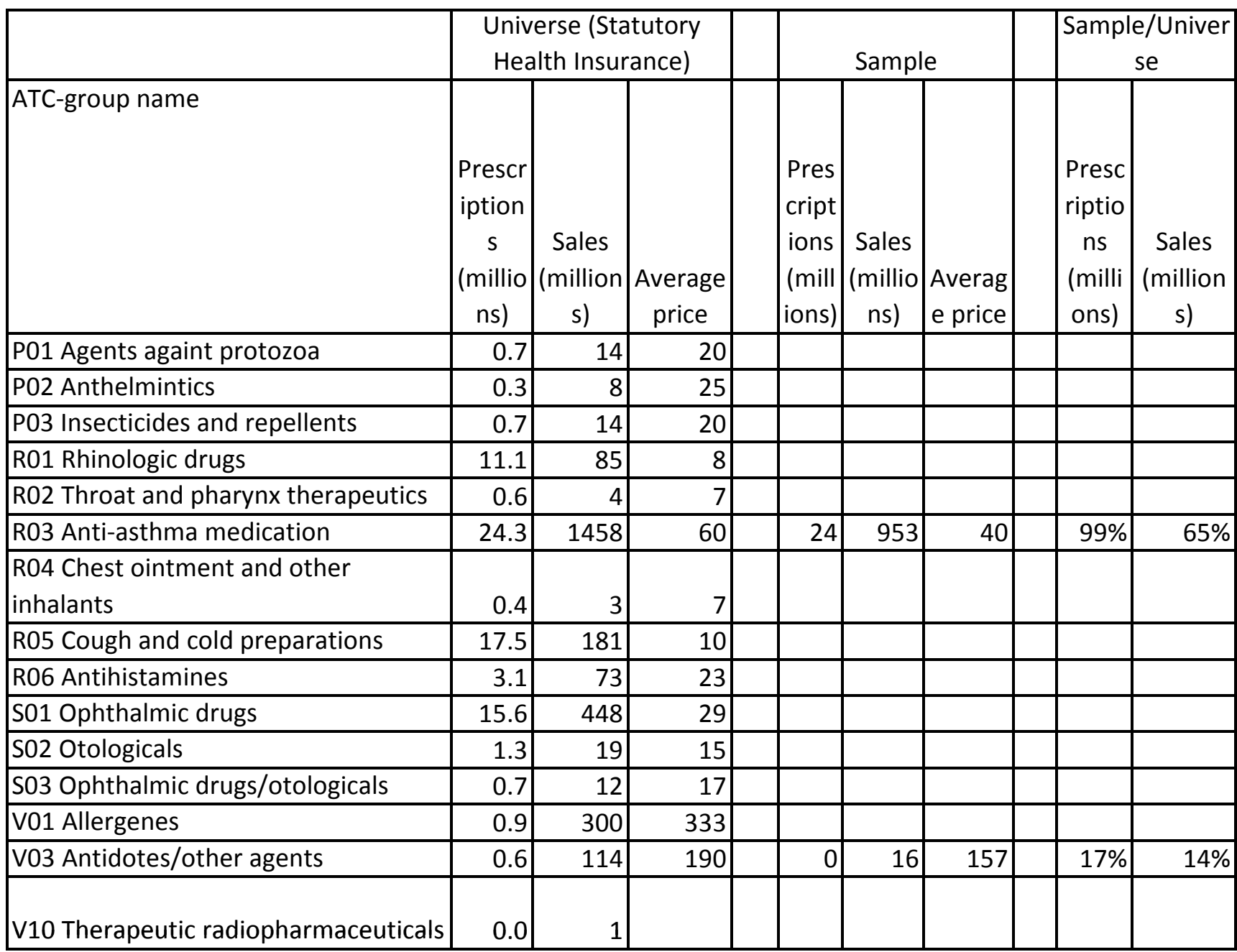

Sales figures from the Statutory Health Insurance are at the level of public price (pharmacy selling price including VAT), whereas sales figures from IMS in the sample are at the level of ex-factory price. According to the VFA (http://www.vfa.de/en/statistics/pharmaceuticalmarket/), sales at ex-factory price level accounted for $58 \%$ of sales at public price level ( $23.8 \mathrm{bn}$. EUR of $41 \mathrm{bn}$. EUR) in the total pharmacy market (=SHI + private insurance $+\mathrm{OTC}$ ). Therefore the sample covers approx. $50 \%$ of SHI pharmaceutical expenditures rather than the directly calculated $29 \%$ shown in the table. Also, SHI data are based on the ATC drug classification, while IMS data are based on the EphMRA classification, which may cause some drugs to be classified differently between "universe" and sample.

Pharmaceutical groups in the Statutory Health Insurance (prescriptions in millions, turnover in million $€$ ). Classification: years, Germany, ATC-groups (2. level) http://www.gbe-bund.de/

Home > Health Care System > Pharmaceutical Supply, Aids and Appliances/Non-medical Therapy > Pharmaceuticals > Table (ad hoc): Pharmaceutical by ATC-groups

Year: 2008 
Appendix Table 2

Complete German dataset

\begin{tabular}{|c|c|c|c|c|c|c|c|c|c|c|c|c|c|}
\hline 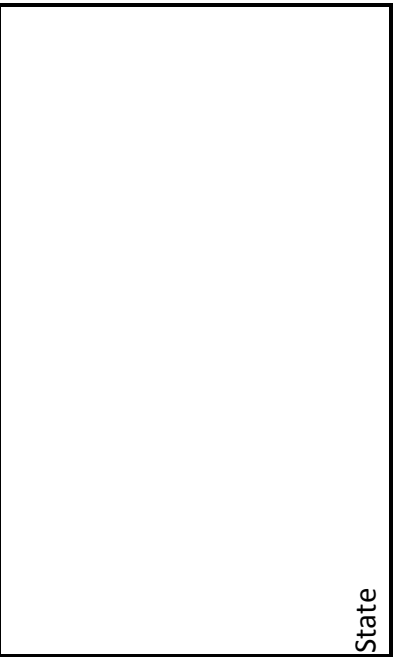 & $\begin{array}{l}\stackrel{\bar{\pi}}{ٍ ٍ ~} \\
\stackrel{2}{2}\end{array}$ & 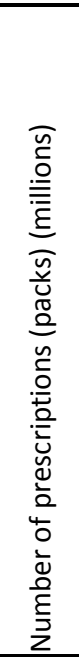 & 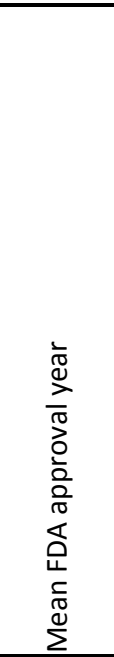 & 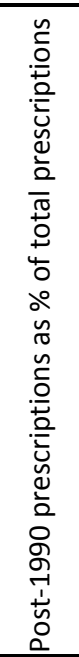 & 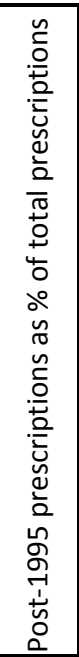 & 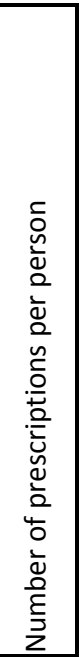 & 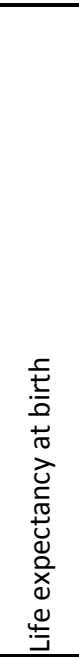 & 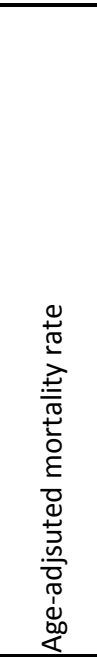 & 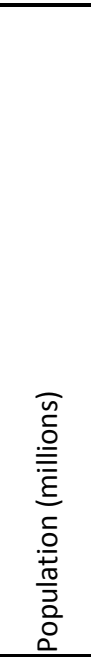 & 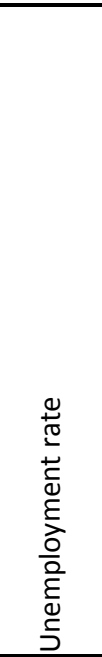 & 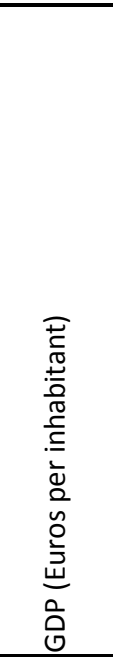 & 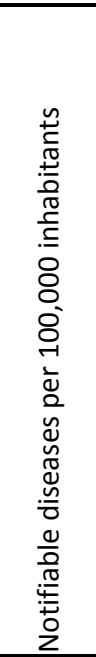 & 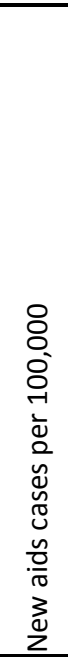 \\
\hline Baden-Wuerttemberg & 2000 & 25.2 & 1983.3 & $33 \%$ & $8 \%$ & 2.41 & 79.2 & 810.6 & 10.49 & $4.1 \%$ & 28,343 & & 0.32 \\
\hline Baden-Wuerttemberg & 2001 & 26.6 & 1983.9 & $36 \%$ & $10 \%$ & 2.52 & 79.6 & 782.9 & 10.56 & $3.7 \%$ & 29,308 & 284.1 & 0.36 \\
\hline Baden-Wuerttemberg & 2002 & 27.4 & 1984.3 & $37 \%$ & $11 \%$ & 2.58 & 79.7 & 778.0 & 10.63 & $4.4 \%$ & 29,350 & 257.9 & 0.23 \\
\hline Baden-Wuerttemberg & 2003 & 28.9 & 1984.6 & $38 \%$ & $13 \%$ & 2.71 & 79.8 & 783.1 & 10.68 & $5.7 \%$ & 29,530 & 229.8 & 0.19 \\
\hline Baden-Wuerttemberg & 2004 & 26.1 & 1985.1 & $41 \%$ & $14 \%$ & 2.44 & 80.5 & 725.9 & 10.71 & $6.6 \%$ & 29,845 & 230.3 & 0.27 \\
\hline Baden-Wuerttemberg & 2005 & 26.6 & 1985.1 & $42 \%$ & $12 \%$ & 2.48 & 80.6 & 721.7 & 10.73 & $7.0 \%$ & & 252.4 & 0.26 \\
\hline Baden-Wuerttemberg & 2006 & 27.1 & 1985.5 & $44 \%$ & $13 \%$ & 2.52 & 81.0 & 692.9 & 10.74 & $6.3 \%$ & 31,427 & 279.9 & 0.17 \\
\hline Baden-Wuerttemberg & 2007 & 27.9 & 1985.9 & $46 \%$ & $14 \%$ & 2.60 & 81.1 & 687.0 & 10.75 & $4.9 \%$ & & 402.8 & 0.15 \\
\hline Baden-Wuerttemberg & 2008 & 29.0 & 1986.2 & $48 \%$ & $15 \%$ & & & & & $4.2 \%$ & & & \\
\hline Bayern & 2000 & 30.0 & 1983.1 & $34 \%$ & $8 \%$ & 2.46 & 78.5 & 858.5 & 12.19 & $4.0 \%$ & 29,487 & & 0.48 \\
\hline Bayern & 2001 & 31.8 & 1983.9 & $37 \%$ & $10 \%$ & 2.59 & 78.8 & 833.5 & 12.28 & $3.8 \%$ & 30,090 & 234.4 & 0.42 \\
\hline Bayern & 2002 & 32.5 & 1984.3 & $39 \%$ & $11 \%$ & 2.63 & 78.9 & 831.6 & 12.36 & $4.5 \%$ & 30,671 & 255.0 & 0.37 \\
\hline Bayern & 2003 & 34.4 & 1984.6 & $40 \%$ & $12 \%$ & 2.77 & 79.0 & 834.5 & 12.40 & $6.1 \%$ & 30,783 & 234.9 & 0.30 \\
\hline Bayern & 2004 & 30.5 & 1985.0 & $43 \%$ & $13 \%$ & 2.46 & 79.7 & 783.4 & 12.43 & $6.8 \%$ & 31,601 & 244.1 & 0.43 \\
\hline Bayern & 2005 & 31.4 & 1985.2 & $44 \%$ & $12 \%$ & 2.52 & 79.7 & 780.5 & 12.46 & $7.0 \%$ & & 292.5 & 0.32 \\
\hline Bayern & 2006 & 32.1 & 1985.6 & $46 \%$ & $13 \%$ & 2.57 & 80.0 & 762.8 & 12.48 & $6.5 \%$ & 33,217 & 295.2 & 0.27 \\
\hline Bayern & 2007 & 32.7 & 1985.9 & $48 \%$ & $14 \%$ & 2.61 & 80.2 & 744.3 & 12.50 & $5.3 \%$ & & 427.3 & 0.23 \\
\hline Bayern & 2008 & 33.9 & 1986.3 & $50 \%$ & $15 \%$ & & & & & $4.2 \%$ & & & \\
\hline Berlin & 2000 & 8.6 & 1982.8 & $30 \%$ & $9 \%$ & 2.54 & 78.0 & 879.0 & 3.38 & $14.4 \%$ & 23,162 & & 6.50 \\
\hline Berlin & 2001 & 8.9 & 1983.3 & $32 \%$ & $10 \%$ & 2.63 & 78.4 & 855.2 & 3.39 & $15.1 \%$ & 23,245 & 351.7 & 5.11 \\
\hline Berlin & 2002 & 9.5 & 1983.7 & $34 \%$ & $11 \%$ & 2.79 & 78.2 & 866.3 & 3.39 & $15.6 \%$ & 23,210 & 417.0 & 5.10 \\
\hline Berlin & 2003 & 10.1 & 1984.0 & $35 \%$ & $12 \%$ & 2.99 & 78.5 & 857.4 & 3.39 & $18.0 \%$ & 23,046 & 340.2 & 5.04 \\
\hline Berlin & 2004 & 9.0 & 1984.3 & $37 \%$ & $13 \%$ & 2.65 & 79.1 & 814.7 & 3.39 & $19.1 \%$ & 22,896 & 392.2 & 5.79 \\
\hline Berlin & 2005 & 9.1 & 1984.5 & $38 \%$ & $12 \%$ & 2.70 & 79.2 & 802.1 & 3.39 & $19.2 \%$ & & 465.2 & 5.22 \\
\hline Berlin & 2006 & 9.4 & 1985.0 & $40 \%$ & $13 \%$ & 2.77 & 79.5 & 774.7 & 3.40 & $18.7 \%$ & 23,689 & 425.3 & 5.50 \\
\hline Berlin & 2007 & 9.4 & 1985.5 & $43 \%$ & $14 \%$ & 2.77 & 79.9 & 752.6 & 3.41 & $16.3 \%$ & & 654.1 & 5.05 \\
\hline Berlin & 2008 & 9.8 & 1986.0 & $46 \%$ & $15 \%$ & & & & & $15.1 \%$ & & & \\
\hline Brandenburg & 2000 & 8.2 & 1983.2 & $31 \%$ & $9 \%$ & 3.16 & 77.1 & 965.6 & 2.60 & $16.3 \%$ & 17,298 & & 0.38 \\
\hline Brandenburg & 2001 & 8.5 & 1983.7 & $33 \%$ & $10 \%$ & 3.29 & 77.5 & 933.5 & 2.60 & $16.9 \%$ & 17,697 & 372.5 & 0.27 \\
\hline Brandenburg & 2002 & 8.8 & 1984.2 & $35 \%$ & $11 \%$ & 3.39 & 77.6 & 934.1 & 2.59 & $16.9 \%$ & 18,015 & 509.7 & 0.54 \\
\hline Brandenburg & 2003 & 9.5 & 1984.7 & $37 \%$ & $13 \%$ & 3.69 & 77.6 & 931.5 & 2.58 & $18.3 \%$ & 18,199 & 465.5 & 0.43 \\
\hline Brandenburg & 2004 & 8.4 & 1985.2 & $39 \%$ & $14 \%$ & 3.27 & 78.2 & 875.5 & 2.57 & $19.2 \%$ & 18,778 & 479.3 & 0.54 \\
\hline Brandenburg & 2005 & 8.7 & 1985.3 & $40 \%$ & $13 \%$ & 3.38 & 78.6 & 853.9 & 2.56 & $18.1 \%$ & & 541.2 & 0.23 \\
\hline Brandenburg & 2006 & 8.9 & 1985.6 & $42 \%$ & $13 \%$ & 3.47 & 78.8 & 837.9 & 2.55 & $16.5 \%$ & 19,652 & 518.7 & 0.74 \\
\hline Brandenburg & 2007 & 9.0 & 1986.0 & $44 \%$ & $14 \%$ & 3.53 & 79.0 & 825.3 & 2.54 & $13.8 \%$ & & 879.5 & 0.90 \\
\hline Brandenburg & 2008 & 9.3 & 1986.5 & $47 \%$ & $15 \%$ & & & & & $11.5 \%$ & & & \\
\hline Bremen & 2000 & 2.0 & 1982.5 & $30 \%$ & $8 \%$ & 2.96 & 77.4 & 883.8 & 0.66 & $10.0 \%$ & 33,423 & & 1.21 \\
\hline Bremen & 2001 & 2.0 & 1982.9 & $32 \%$ & $9 \%$ & 3.05 & 77.9 & 849.4 & 0.66 & $8.7 \%$ & 34,421 & 271.8 & 1.21 \\
\hline Bremen & 2002 & 2.1 & 1983.1 & $33 \%$ & $9 \%$ & 3.13 & 77.8 & 871.2 & 0.66 & $10.0 \%$ & 35,279 & 429.5 & 1.51 \\
\hline
\end{tabular}


Appendix Table 2

Complete German dataset

\begin{tabular}{|c|c|c|c|c|c|c|c|c|c|c|c|c|c|}
\hline 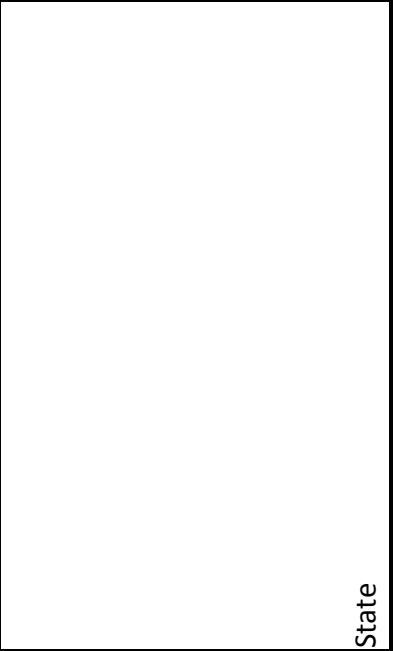 & $\stackrel{\frac{1}{\pi}}{\stackrel{2}{\nu}}$ & 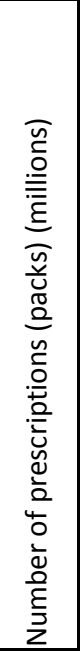 & 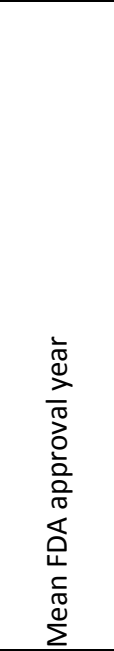 & 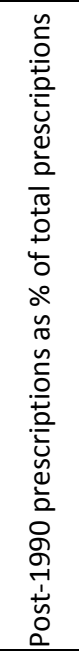 & 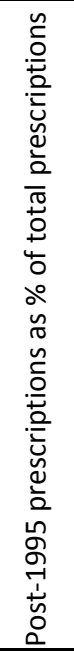 & 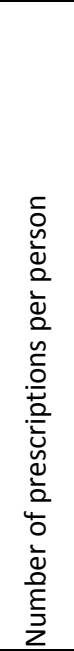 & 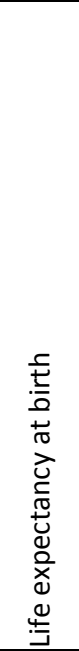 & 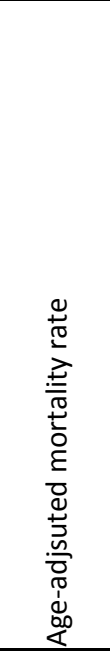 & 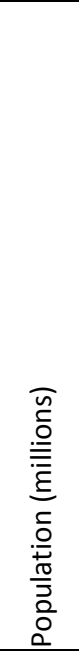 & 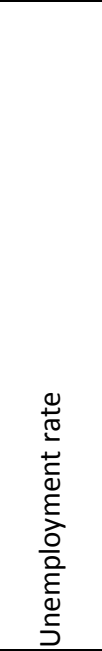 & 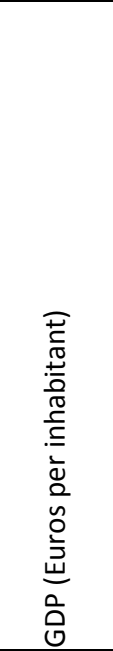 & 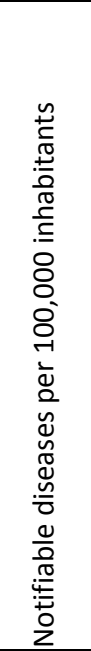 & 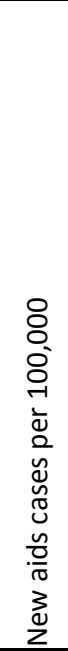 \\
\hline Bremen & 2003 & 2.1 & 1983.2 & $33 \%$ & $9 \%$ & 3.23 & 78.1 & 863.3 & 0.66 & $11.4 \%$ & 35,904 & 319.0 & 0.45 \\
\hline Bremen & 2004 & 1.9 & 1983.4 & $35 \%$ & $9 \%$ & 2.85 & 78.6 & 820.8 & 0.66 & $14.6 \%$ & 36,666 & 332.4 & 0.75 \\
\hline Bremen & 2005 & 1.9 & 1983.7 & $37 \%$ & $9 \%$ & 2.93 & 78.7 & 812.7 & 0.66 & $16.5 \%$ & & 316.2 & 0.60 \\
\hline Bremen & 2006 & 2.0 & 1984.1 & $38 \%$ & $10 \%$ & 2.96 & 79.2 & 777.4 & 0.66 & $14.4 \%$ & 38,211 & 231.8 & 1.96 \\
\hline Bremen & 2007 & 2.0 & 1984.4 & $40 \%$ & $11 \%$ & 3.05 & 79.0 & 778.3 & 0.66 & $11.9 \%$ & & 444.6 & 1.06 \\
\hline Bremen & 2008 & 2.1 & 1984.8 & $42 \%$ & $11 \%$ & & & & & $9.5 \%$ & & & \\
\hline Hamburg & 2000 & 4.5 & 1983.1 & $31 \%$ & $8 \%$ & 2.65 & 78.3 & 849.6 & 1.71 & $7.7 \%$ & 42,422 & & 4.27 \\
\hline Hamburg & 2001 & 4.7 & 1983.5 & $33 \%$ & $10 \%$ & 2.72 & 78.7 & 820.7 & 1.72 & $7.0 \%$ & 44,402 & 360.0 & 4.13 \\
\hline Hamburg & 2002 & 4.8 & 1983.9 & $34 \%$ & $11 \%$ & 2.81 & 78.6 & 841.5 & 1.73 & $8.2 \%$ & 44,908 & 466.2 & 4.05 \\
\hline Hamburg & 2003 & 4.9 & 1984.1 & $35 \%$ & $12 \%$ & 2.85 & 78.8 & 829.6 & 1.73 & $9.6 \%$ & 45,020 & 357.9 & 4.44 \\
\hline Hamburg & 2004 & 4.4 & 1984.3 & $36 \%$ & $12 \%$ & 2.54 & 79.2 & 801.6 & 1.74 & $10.6 \%$ & 45,724 & 369.7 & 4.55 \\
\hline Hamburg & 2005 & 4.4 & 1984.5 & $37 \%$ & $11 \%$ & 2.52 & 79.5 & 782.9 & 1.74 & $10.4 \%$ & & 385.3 & 3.56 \\
\hline Hamburg & 2006 & 4.4 & 1984.9 & $39 \%$ & $12 \%$ & 2.54 & 79.9 & 762.6 & 1.75 & $9.8 \%$ & 48,611 & 509.7 & 3.03 \\
\hline Hamburg & 2007 & 4.5 & 1985.3 & $41 \%$ & $13 \%$ & 2.55 & 80.0 & 753.2 & 1.76 & $8.9 \%$ & & 705.4 & 2.72 \\
\hline Hamburg & 2008 & 4.6 & 1985.7 & $44 \%$ & $14 \%$ & & & & & $7.1 \%$ & & & \\
\hline Hessen & 2000 & 16.2 & 1982.6 & $31 \%$ & $7 \%$ & 2.67 & 78.6 & 856.5 & 6.06 & $5.8 \%$ & 30,223 & & 1.54 \\
\hline Hessen & 2001 & 17.0 & 1983.1 & $33 \%$ & $9 \%$ & 2.79 & 79.0 & 825.1 & 6.07 & $5.5 \%$ & 31,203 & 224.2 & 1.45 \\
\hline Hessen & 2002 & 17.4 & 1983.4 & $34 \%$ & $10 \%$ & 2.86 & 78.9 & 828.9 & 6.08 & $5.9 \%$ & 31,407 & 242.0 & 1.28 \\
\hline Hessen & 2003 & 18.2 & 1983.8 & $36 \%$ & $11 \%$ & 2.99 & 78.9 & 835.8 & 6.09 & $7.1 \%$ & 32,151 & 228.8 & 1.10 \\
\hline Hessen & 2004 & 16.4 & 1984.3 & $38 \%$ & $12 \%$ & 2.69 & 79.6 & 784.0 & 6.09 & $7.9 \%$ & 32,641 & 224.1 & 1.23 \\
\hline Hessen & 2005 & 16.7 & 1984.6 & $40 \%$ & $12 \%$ & 2.74 & 79.9 & 762.8 & 6.09 & $8.4 \%$ & & 244.4 & 1.15 \\
\hline Hessen & 2006 & 16.9 & 1985.1 & $42 \%$ & $13 \%$ & 2.78 & 80.3 & 736.5 & 6.08 & $8.1 \%$ & 34,369 & 243.7 & 1.00 \\
\hline Hessen & 2007 & 17.0 & 1985.5 & $44 \%$ & $13 \%$ & 2.81 & 80.3 & 740.2 & 6.07 & $7.3 \%$ & & 425.3 & 0.64 \\
\hline Hessen & 2008 & 17.5 & 1985.9 & $47 \%$ & $15 \%$ & & & & & $6.4 \%$ & & & \\
\hline Mecklenburg-Vorpommern & 2000 & 6.4 & 1983.1 & $31 \%$ & $9 \%$ & 3.59 & 76.4 & 1000.6 & 1.78 & $16.4 \%$ & 16,860 & & 0.17 \\
\hline Mecklenburg-Vorpommern & 2001 & 6.6 & 1983.8 & $34 \%$ & $11 \%$ & 3.74 & 76.9 & 958.8 & 1.77 & $18.5 \%$ & 17,343 & 456.7 & 0.45 \\
\hline Mecklenburg-Vorpommern & 2002 & 6.8 & 1984.3 & $35 \%$ & $12 \%$ & 3.89 & 77.1 & 947.5 & 1.75 & $19.1 \%$ & 17,624 & 739.0 & 0.40 \\
\hline Mecklenburg-Vorpommern & 2003 & 7.3 & 1985.0 & $38 \%$ & $14 \%$ & 4.19 & 77.2 & 947.2 & 1.74 & $20.2 \%$ & 17,904 & 621.9 & 0.52 \\
\hline Mecklenburg-Vorpommern & 2004 & 6.4 & 1985.5 & $40 \%$ & $15 \%$ & 3.69 & 77.8 & 895.9 & 1.73 & $22.1 \%$ & 18,450 & 681.2 & 0.46 \\
\hline Mecklenburg-Vorpommern & 2005 & 6.6 & 1985.7 & $42 \%$ & $14 \%$ & 3.83 & 78.0 & 882.1 & 1.71 & $21.3 \%$ & & 664.0 & 0.41 \\
\hline Mecklenburg-Vorpommern & 2006 & 6.7 & 1986.1 & $43 \%$ & $15 \%$ & 3.94 & 78.5 & 851.5 & 1.70 & $19.2 \%$ & 19,193 & 707.9 & 0.24 \\
\hline Mecklenburg-Vorpommern & 2007 & 6.7 & 1986.4 & $45 \%$ & $15 \%$ & 3.98 & 78.7 & 843.5 & 1.69 & $17.4 \%$ & & 981.6 & 0.18 \\
\hline Mecklenburg-Vorpommern & 2008 & 7.0 & 1986.9 & $48 \%$ & $16 \%$ & & & & & $14.6 \%$ & & & \\
\hline Niedersachsen & 2000 & 21.7 & 1982.6 & $30 \%$ & $7 \%$ & 2.74 & 78.0 & 884.6 & 7.91 & $6.6 \%$ & 22,767 & & 0.34 \\
\hline Niedersachsen & 2001 & 23.1 & 1983.1 & $32 \%$ & $9 \%$ & 2.91 & 78.4 & 860.5 & 7.94 & $6.4 \%$ & 22,904 & 257.0 & 0.43 \\
\hline Niedersachsen & 2002 & 24.2 & 1983.5 & $34 \%$ & $10 \%$ & 3.04 & 78.4 & 860.7 & 7.97 & $7.2 \%$ & 22,796 & 333.2 & 0.43 \\
\hline Niedersachsen & 2003 & 25.6 & 1983.9 & $35 \%$ & $11 \%$ & 3.21 & 78.3 & 868.9 & 7.99 & $8.5 \%$ & 22,965 & 277.3 & 0.43 \\
\hline Niedersachsen & 2004 & 22.6 & 1984.3 & $37 \%$ & $12 \%$ & 2.82 & 79.0 & 815.2 & 8.00 & $9.5 \%$ & 23,402 & 279.3 & 0.48 \\
\hline Niedersachsen & 2005 & 23.0 & 1984.5 & $39 \%$ & $11 \%$ & 2.88 & 79.2 & 807.7 & 8.00 & $10.4 \%$ & & 295.2 & 0.43 \\
\hline
\end{tabular}


Appendix Table 2

Complete German dataset

\begin{tabular}{|c|c|c|c|c|c|c|c|c|c|c|c|c|c|}
\hline 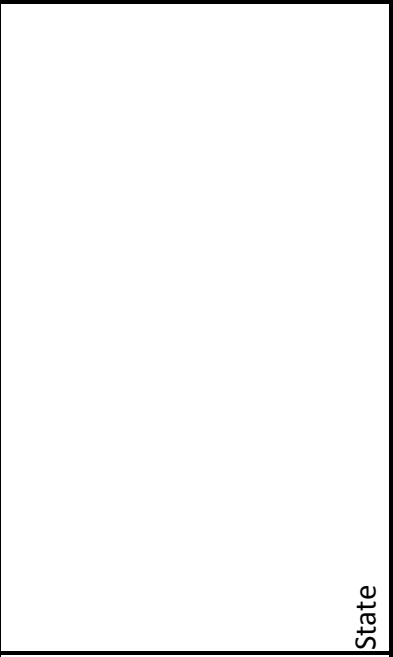 & 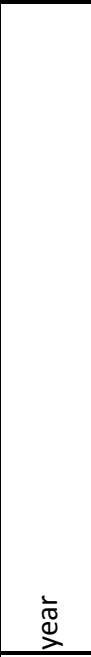 & 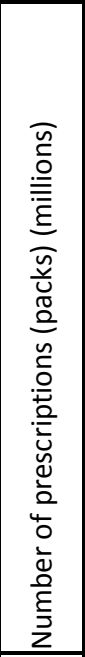 & 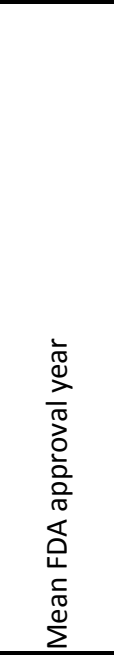 & 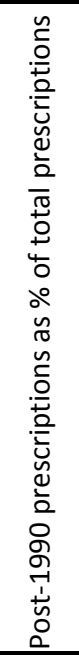 & 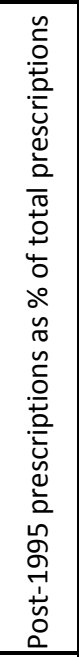 & 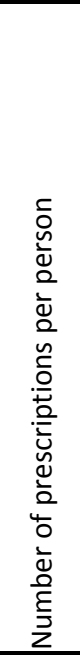 & 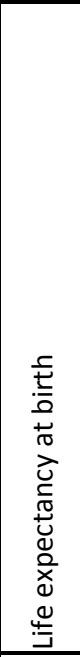 & 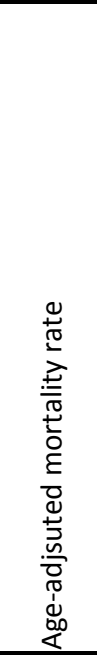 & 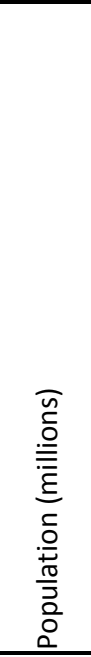 & 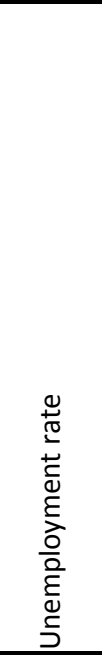 & 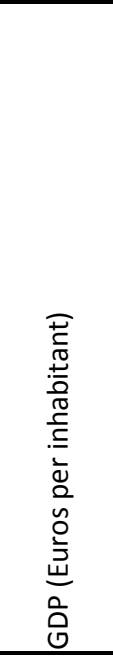 & 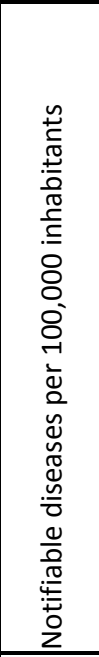 & 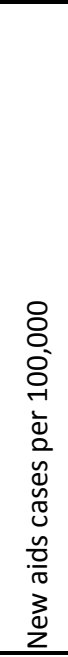 \\
\hline Niedersachsen & 2006 & 23.5 & 1984.8 & $40 \%$ & $12 \%$ & 2.94 & 79.5 & 784.2 & 7.99 & $9.7 \%$ & 24,897 & 311.4 & 0.41 \\
\hline Niedersachsen & 2007 & 24.1 & 1985.2 & $42 \%$ & $13 \%$ & 3.03 & 79.7 & 771.6 & 7.98 & $7.9 \%$ & & 434.3 & 0.45 \\
\hline Niedersachsen & 2008 & 25.0 & 1985.5 & $44 \%$ & $14 \%$ & & & & & $7.1 \%$ & & & \\
\hline Nordrhein-Westfalen & 2000 & 52.2 & 1983.0 & $31 \%$ & $8 \%$ & 1.51 & 77.9 & 906.3 & 18.00 & $6.5 \%$ & 25,236 & & 1.33 \\
\hline Nordrhein-Westfalen & 2001 & 54.7 & 1983.4 & $34 \%$ & $10 \%$ & 1.53 & 78.2 & 877.1 & 18.03 & $6.0 \%$ & 25,622 & 242.7 & 1.20 \\
\hline Nordrhein-Westfalen & 2002 & 56.4 & 1983.7 & $35 \%$ & $10 \%$ & 1.61 & 78.2 & 880.9 & 18.06 & $7.2 \%$ & 25,944 & 243.4 & 1.13 \\
\hline Nordrhein-Westfalen & 2003 & 59.1 & 1984.1 & $36 \%$ & $11 \%$ & 1.69 & 78.2 & 883.6 & 18.08 & $8.8 \%$ & 26,073 & 232.4 & 1.15 \\
\hline Nordrhein-Westfalen & 2004 & 52.5 & 1984.5 & $38 \%$ & $12 \%$ & 1.50 & 78.8 & 840.3 & 18.07 & $9.5 \%$ & 26,728 & 254.6 & 1.00 \\
\hline Nordrhein-Westfalen & 2005 & 53.6 & 1984.6 & $39 \%$ & $11 \%$ & 1.53 & 78.9 & 828.7 & 18.06 & $10.4 \%$ & & 290.9 & 1.01 \\
\hline Nordrhein-Westfalen & 2006 & 53.9 & 1984.9 & $40 \%$ & $12 \%$ & 1.54 & 79.4 & 799.7 & 18.04 & $9.8 \%$ & 28,022 & 311.8 & 0.98 \\
\hline Nordrhein-Westfalen & 2007 & 55.3 & 1985.3 & $42 \%$ & $12 \%$ & 1.58 & 79.4 & 791.4 & 18.01 & $8.3 \%$ & & 493.6 & 0.92 \\
\hline Nordrhein-Westfalen & 2008 & 57.2 & 1985.6 & $44 \%$ & $13 \%$ & & & & & $7.4 \%$ & & & \\
\hline Rheinland-Pfalz & 2000 & 11.8 & 1983.2 & $33 \%$ & $8 \%$ & 2.94 & 78.1 & 885.0 & 4.03 & $5.8 \%$ & 22,587 & & 0.67 \\
\hline Rheinland-Pfalz & 2001 & 12.2 & 1983.7 & $35 \%$ & $10 \%$ & 3.03 & 78.4 & 867.5 & 4.04 & $5.0 \%$ & 22,531 & 279.7 & 0.74 \\
\hline Rheinland-Pfalz & 2002 & 12.8 & 1984.0 & $36 \%$ & $10 \%$ & 3.16 & 78.5 & 865.3 & 4.05 & $5.6 \%$ & 23,042 & 345.8 & 0.47 \\
\hline Rheinland-Pfalz & 2003 & 13.5 & 1984.2 & $37 \%$ & $11 \%$ & 3.32 & 78.4 & 879.7 & 4.06 & $6.3 \%$ & 23,161 & 369.6 & 0.35 \\
\hline Rheinland-Pfalz & 2004 & 11.9 & 1984.7 & $39 \%$ & $12 \%$ & 2.94 & 79.2 & 819.3 & 4.06 & $7.0 \%$ & 23,853 & 386.6 & 0.15 \\
\hline Rheinland-Pfalz & 2005 & 12.2 & 1984.9 & $41 \%$ & $12 \%$ & 3.02 & 79.2 & 818.6 & 4.06 & $8.7 \%$ & & 388.5 & 0.39 \\
\hline Rheinland-Pfalz & 2006 & 12.4 & 1985.3 & $42 \%$ & $13 \%$ & 3.06 & 79.7 & 786.9 & 4.05 & $8.0 \%$ & 24,618 & 362.4 & 0.44 \\
\hline Rheinland-Pfalz & 2007 & \begin{tabular}{|l|}
12.7 \\
\end{tabular} & 1985.7 & $44 \%$ & $14 \%$ & 3.14 & 79.8 & 774.7 & 4.05 & $6.0 \%$ & & 632.6 & 0.22 \\
\hline Rheinland-Pfalz & 2008 & 13.2 & 1986.1 & $47 \%$ & $15 \%$ & & & & & $5.6 \%$ & & & \\
\hline Saarland & 2000 & 2.8 & 1983.0 & $32 \%$ & $8 \%$ & 2.62 & 77.1 & 961.9 & 1.07 & $7.3 \%$ & 23,124 & & 0.19 \\
\hline Saarland & 2001 & 2.9 & 1983.6 & $34 \%$ & $9 \%$ & 2.76 & 77.3 & 946.2 & 1.07 & $5.9 \%$ & 23,566 & 230.8 & 0.19 \\
\hline Saarland & 2002 & 3.9 & 1984.0 & $36 \%$ & $10 \%$ & 3.69 & 77.6 & 937.4 & 1.07 & $7.6 \%$ & 23,691 & 342.4 & 0.38 \\
\hline Saarland & 2003 & 4.1 & 1984.3 & $37 \%$ & $12 \%$ & 3.87 & 77.1 & 960.9 & 1.06 & $8.3 \%$ & 23,939 & 281.3 & 0.19 \\
\hline Saarland & 2004 & 3.6 & 1984.8 & $39 \%$ & $13 \%$ & 3.40 & 78.2 & 886.3 & 1.06 & $8.7 \%$ & 25,170 & 291.0 & \\
\hline Saarland & 2005 & 3.7 & 1984.9 & $41 \%$ & $12 \%$ & 3.49 & 78.3 & 886.3 & 1.05 & $10.8 \%$ & & 335.9 & \\
\hline Saarland & 2006 & 3.7 & 1985.3 & $42 \%$ & $13 \%$ & 3.51 & 78.4 & 867.4 & 1.05 & $9.5 \%$ & 27,317 & 300.0 & \\
\hline Saarland & 2007 & 3.7 & 1985.7 & $45 \%$ & $14 \%$ & 3.52 & 78.7 & 852.5 & 1.04 & $7.3 \%$ & & 475.4 & \\
\hline Saarland & 2008 & 3.7 & 1986.1 & $47 \%$ & $15 \%$ & & & & & $7.1 \%$ & & & \\
\hline Sachsen & 2000 & 15.6 & 1983.1 & $30 \%$ & $8 \%$ & 3.51 & 77.8 & 901.1 & 4.44 & $16.1 \%$ & 17,032 & & 0.14 \\
\hline Sachsen & 2001 & \begin{tabular}{|l|}
16.2 \\
\end{tabular} & 1983.8 & $33 \%$ & $10 \%$ & 3.67 & 78.4 & 860.3 & 4.40 & $17.0 \%$ & 17,731 & 540.8 & 0.11 \\
\hline Sachsen & 2002 & 16.6 & 1984.4 & $35 \%$ & $12 \%$ & 3.80 & 78.4 & 865.9 & 4.37 & $17.8 \%$ & 18,632 & 733.9 & 0.14 \\
\hline Sachsen & 2003 & \begin{tabular}{|l|}
17.5 \\
\end{tabular} & 1985.0 & $37 \%$ & $13 \%$ & 4.04 & 78.4 & 868.4 & 4.33 & $17.8 \%$ & 19,187 & 645.4 & 0.05 \\
\hline Sachsen & 2004 & 15.5 & 1985.4 & $39 \%$ & $14 \%$ & 3.61 & 79.1 & 812.4 & 4.31 & $19.4 \%$ & 19,860 & 698.9 & 0.05 \\
\hline Sachsen & 2005 & 15.9 & 1985.7 & $41 \%$ & $14 \%$ & 3.71 & 79.3 & 801.3 & 4.28 & $18.7 \%$ & & 745.3 & 0.28 \\
\hline Sachsen & 2006 & 16.3 & 1986.2 & $43 \%$ & $15 \%$ & 3.81 & 79.7 & 773.0 & 4.26 & $16.6 \%$ & 20,747 & 716.0 & 0.16 \\
\hline Sachsen & 2007 & 16.1 & 1986.6 & $45 \%$ & $16 \%$ & 3.81 & 79.7 & 772.0 & 4.23 & $14.4 \%$ & & 974.7 & 0.24 \\
\hline Sachsen & 2008 & 16.4 & 1987.0 & $47 \%$ & $17 \%$ & & & & & $12.9 \%$ & & & \\
\hline
\end{tabular}


Appendix Table 2

Complete German dataset

\begin{tabular}{|c|c|c|c|c|c|c|c|c|c|c|c|c|c|}
\hline 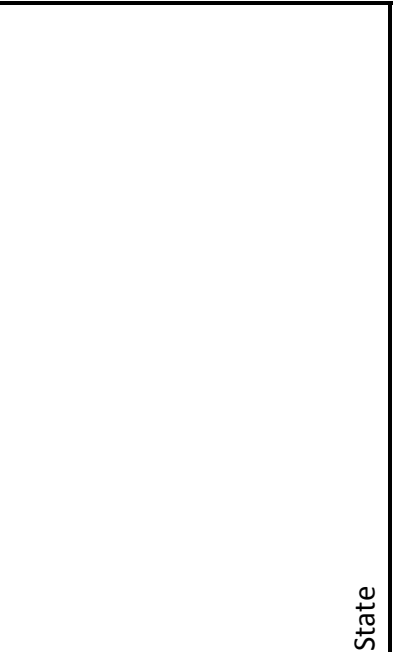 & 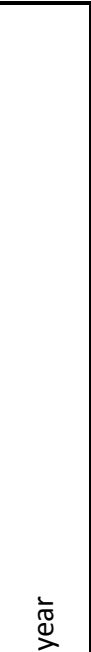 & 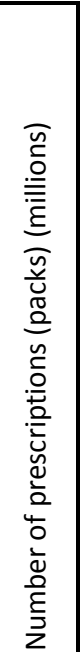 & 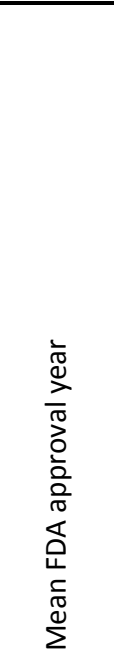 & 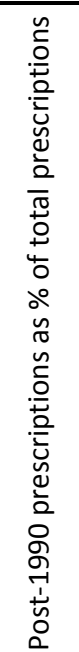 & 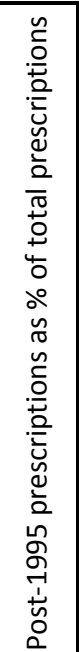 & 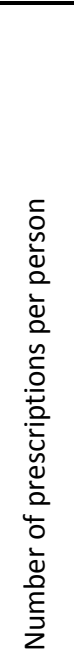 & 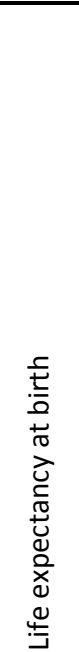 & 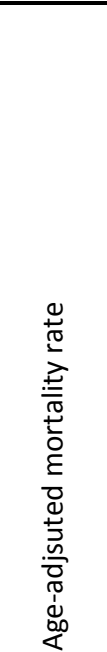 & 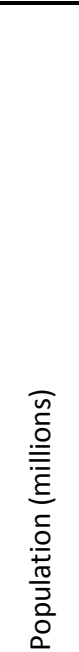 & 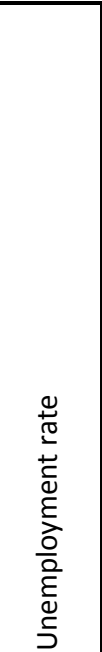 & 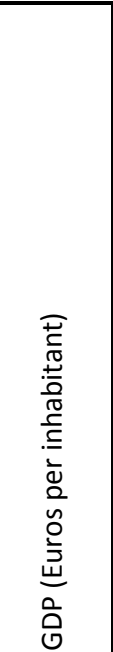 & 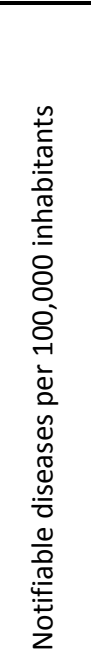 & 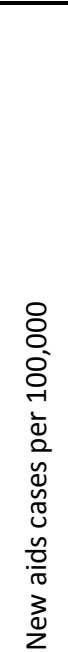 \\
\hline Sachsen-Anhalt & 2000 & 9.7 & 1982.7 & $30 \%$ & $8 \%$ & 3.68 & 76.5 & 1000.8 & 2.63 & $20.2 \%$ & 16,437 & & 0.19 \\
\hline Sachsen-Anhalt & 2001 & 9.9 & 1983.4 & $32 \%$ & $10 \%$ & 3.83 & 77.0 & 965.7 & 2.60 & $19.9 \%$ & 16,937 & 561.9 & 0.23 \\
\hline Sachsen-Anhalt & 2002 & 10.2 & 1983.8 & $33 \%$ & $11 \%$ & 3.98 & 76.9 & 972.3 & 2.56 & $19.2 \%$ & 17,848 & 680.5 & 0.08 \\
\hline Sachsen-Anhalt & 2003 & 10.9 & 1984.3 & $36 \%$ & $13 \%$ & 4.30 & 77.3 & 945.8 & 2.54 & $19.9 \%$ & 18,165 & 554.6 & 0.32 \\
\hline Sachsen-Anhalt & 2004 & 9.6 & 1984.8 & $37 \%$ & $14 \%$ & 3.83 & 77.7 & 907.8 & 2.51 & $22.4 \%$ & 18,758 & 500.2 & 0.32 \\
\hline Sachsen-Anhalt & 2005 & 9.8 & 1985.0 & $39 \%$ & $13 \%$ & 3.95 & 77.9 & 894.9 & 2.48 & $20.3 \%$ & & 574.8 & 0.20 \\
\hline Sachsen-Anhalt & 2006 & 9.9 & 1985.4 & $40 \%$ & $14 \%$ & 4.03 & 78.3 & 870.9 & 2.46 & $17.8 \%$ & 20,057 & 540.2 & 0.33 \\
\hline Sachsen-Anhalt & 2007 & 10.0 & 1985.7 & $42 \%$ & $15 \%$ & 4.14 & 78.5 & 862.7 & 2.43 & $15.7 \%$ & & 813.1 & 0.12 \\
\hline Sachsen-Anhalt & 2008 & 10.4 & 1986.2 & $45 \%$ & $16 \%$ & & & & & $14.6 \%$ & & & \\
\hline Schleswig-Holstein & 2000 & 7.5 & 1983.0 & $33 \%$ & $8 \%$ & 2.69 & 78.1 & 881.9 & 2.78 & $6.4 \%$ & 23,309 & & 0.83 \\
\hline Schleswig-Holstein & 2001 & 7.7 & 1983.4 & $34 \%$ & $10 \%$ & 2.77 & 78.4 & 857.1 & 2.80 & $6.4 \%$ & 23,775 & 265.6 & 0.89 \\
\hline Schleswig-Holstein & 2002 & 8.0 & 1983.7 & $35 \%$ & $10 \%$ & 2.83 & 78.6 & 848.2 & 2.81 & $7.6 \%$ & 23,331 & 295.8 & 0.78 \\
\hline Schleswig-Holstein & 2003 & 8.4 & 1984.1 & $37 \%$ & $11 \%$ & 2.97 & 78.5 & 860.1 & 2.82 & $8.6 \%$ & 23,540 & 267.0 & 1.10 \\
\hline Schleswig-Holstein & 2004 & 7.5 & 1984.4 & $38 \%$ & $12 \%$ & 2.64 & 78.9 & 824.8 & 2.83 & $9.7 \%$ & 23,917 & 248.4 & 1.10 \\
\hline Schleswig-Holstein & 2005 & 7.6 & 1984.6 & $40 \%$ & $11 \%$ & 2.70 & 79.3 & 799.9 & 2.83 & $10.2 \%$ & & 262.5 & 0.95 \\
\hline Schleswig-Holstein & 2006 & 7.8 & 1985.0 & $41 \%$ & $12 \%$ & 2.74 & 79.6 & 784.2 & 2.83 & $9.0 \%$ & 24,680 & 266.0 & 0.95 \\
\hline Schleswig-Holstein & 2007 & 8.0 & 1985.5 & $44 \%$ & $13 \%$ & 2.82 & 79.7 & 774.5 & 2.84 & $7.9 \%$ & & 378.3 & 0.63 \\
\hline Schleswig-Holstein & 2008 & 8.3 & 1985.8 & $45 \%$ & $14 \%$ & & & & & $6.8 \%$ & & & \\
\hline Thueringen & 2000 & 7.6 & 1983.0 & $30 \%$ & $8 \%$ & 3.12 & 77.3 & 965.3 & 2.44 & $13.5 \%$ & 16,638 & & 0.04 \\
\hline Thueringen & 2001 & 7.8 & 1983.7 & $33 \%$ & $10 \%$ & 3.20 & 77.7 & 926.1 & 2.42 & $13.9 \%$ & 17,211 & 490.5 & \\
\hline Thueringen & 2002 & 9.2 & 1984.3 & $35 \%$ & $11 \%$ & 3.84 & 77.8 & 927.1 & 2.40 & $15.1 \%$ & 17,666 & 662.9 & 0.08 \\
\hline Thueringen & 2003 & 9.8 & 1984.9 & $37 \%$ & $13 \%$ & 4.11 & 77.8 & 926.3 & 2.38 & $16.3 \%$ & 18,223 & 541.1 & 0.04 \\
\hline Thueringen & 2004 & 8.6 & 1985.4 & $39 \%$ & $14 \%$ & 3.65 & 78.3 & 872.1 & 2.36 & $16.3 \%$ & 18,878 & 661.0 & \\
\hline Thueringen & 2005 & 8.9 & 1985.7 & $40 \%$ & $13 \%$ & 3.79 & 78.7 & 859.7 & 2.35 & $17.1 \%$ & & 612.3 & 0.04 \\
\hline Thueringen & 2006 & 9.1 & 1986.1 & $42 \%$ & $15 \%$ & 3.91 & 78.8 & 840.0 & 2.32 & $15.6 \%$ & 19,877 & 677.8 & 0.13 \\
\hline Thueringen & 2007 & 9.0 & 1986.4 & $44 \%$ & $15 \%$ & 3.92 & 79.1 & 827.0 & 2.30 & $13.7 \%$ & & 872.6 & \\
\hline Thueringen & 2008 & 9.1 & 1986.9 & $46 \%$ & $16 \%$ & & & & & $10.6 \%$ & & & \\
\hline
\end{tabular}


Appendix Table 3

French cancer data

\begin{tabular}{|c|c|c|c|c|c|c|}
\hline Cancer site & Year & \begin{tabular}{|l} 
Age- \\
adjusted \\
mortality \\
rate (per \\
100,000 \\
pop)
\end{tabular} & $\begin{array}{l}\text { Number of } \\
\text { patients in } \\
\text { IMS } \\
\text { sample }\end{array}$ & \begin{tabular}{|l|} 
Weighted \\
mean world \\
launch year
\end{tabular} & \begin{tabular}{|l|} 
post1985 \\
$\%$
\end{tabular} & \begin{tabular}{|l|} 
post1990 \\
$\%$
\end{tabular} \\
\hline$\overline{A L L}$ & 2002 & 0.45 & 7 & 1975.3 & $14 \%$ & $14 \%$ \\
\hline$\overline{A L L}$ & 2003 & 0.43 & 3 & 2001.0 & $100 \%$ & $100 \%$ \\
\hline$\overline{A L L}$ & 2004 & 0.39 & 14 & 1998.9 & $93 \%$ & $93 \%$ \\
\hline$\overline{A L L}$ & 2005 & 0.34 & 16 & 1987.9 & $56 \%$ & $56 \%$ \\
\hline$\overline{A L L}$ & 2006 & 0.40 & 19 & 1986.8 & $53 \%$ & $53 \%$ \\
\hline AML & 2003 & 2.32 & 1 & 2001.0 & $100 \%$ & $100 \%$ \\
\hline AML & 2005 & 2.40 & 2 & 2001.0 & $100 \%$ & $100 \%$ \\
\hline AML & 2006 & 2.27 & 1 & 2001.0 & $100 \%$ & $100 \%$ \\
\hline BLADDER & 2002 & 7.17 & 32 & 1993.4 & $84 \%$ & $84 \%$ \\
\hline BLADDER & 2003 & 7.53 & 40 & 1991.2 & $63 \%$ & $63 \%$ \\
\hline BLADDER & 2004 & 7.41 & 59 & 1993.1 & $80 \%$ & $80 \%$ \\
\hline BLADDER & 2005 & 7.46 & 71 & 1992.0 & $70 \%$ & $70 \%$ \\
\hline BLADDER & 2006 & 7.19 & 75 & 1991.5 & $65 \%$ & $65 \%$ \\
\hline BRAIN & 2002 & 4.74 & 37 & 1998.8 & $97 \%$ & $97 \%$ \\
\hline BRAIN & 2003 & 4.82 & 46 & 1997.5 & $89 \%$ & $89 \%$ \\
\hline BRAIN & 2004 & 4.58 & 80 & 1996.9 & $85 \%$ & $85 \%$ \\
\hline BRAIN & 2005 & 4.52 & 148 & 1997.1 & $86 \%$ & $86 \%$ \\
\hline BRAIN & 2006 & 4.50 & 150 & 1997.0 & $86 \%$ & $86 \%$ \\
\hline BREAST & 2002 & 19.03 & 664 & 1986.2 & $36 \%$ & $27 \%$ \\
\hline BREAST & 2003 & 18.68 & 792 & 1986.2 & $37 \%$ & $28 \%$ \\
\hline BREAST & 2004 & 18.50 & 926 & 1986.5 & $35 \%$ & $30 \%$ \\
\hline BREAST & 2005 & 18.31 & 1300 & 1987.5 & $42 \%$ & $38 \%$ \\
\hline BREAST & 2006 & 17.99 & 1345 & 1987.8 & $43 \%$ & $39 \%$ \\
\hline CERVIX UTERI & 2005 & 1.18 & 1 & 1984.0 & $0 \%$ & $0 \%$ \\
\hline CERVIX UTERI & 2006 & 1.10 & 1 & 1984.0 & $0 \%$ & $0 \%$ \\
\hline$\overline{\mathrm{CLL}}$ & 2002 & 1.83 & 31 & 1971.0 & $0 \%$ & $0 \%$ \\
\hline$\overline{\mathrm{CLL}}$ & 2003 & 1.90 & 28 & 1972.1 & $4 \%$ & $4 \%$ \\
\hline$\overline{\mathrm{CLL}}$ & 2004 & 1.79 & 23 & 1971.0 & $0 \%$ & $0 \%$ \\
\hline$\overline{\mathrm{CLL}}$ & 2005 & 1.71 & 28 & 1971.0 & $0 \%$ & $0 \%$ \\
\hline$\overline{C L L}$ & 2006 & 1.75 & 36 & 1971.0 & $0 \%$ & $0 \%$ \\
\hline$\overline{\mathrm{CML}}$ & 2002 & 0.93 & 89 & 2001.0 & $100 \%$ & $100 \%$ \\
\hline$\overline{\mathrm{CML}}$ & 2003 & 0.95 & 112 & 2001.0 & $100 \%$ & $100 \%$ \\
\hline$\overline{\mathrm{CML}}$ & 2004 & 0.89 & 126 & 2001.0 & $100 \%$ & $100 \%$ \\
\hline $\mathrm{CML}$ & 2005 & 0.92 & 163 & 2001.0 & $100 \%$ & $100 \%$ \\
\hline$\overline{C M L}$ & 2006 & 0.76 & 158 & 2001.0 & $100 \%$ & $100 \%$ \\
\hline COLORECTAL & 2002 & 27.03 & 22 & 1998.0 & $100 \%$ & $100 \%$ \\
\hline COLORECTAL & 2003 & 27.16 & 45 & 1998.0 & $100 \%$ & $100 \%$ \\
\hline COLORECTAL & 2004 & 26.68 & 53 & 1998.2 & $100 \%$ & $100 \%$ \\
\hline COLORECTAL & 2005 & 26.33 & 108 & 1998.0 & $100 \%$ & $100 \%$ \\
\hline COLORECTAL & 2006 & 25.20 & 104 & 1998.1 & $100 \%$ & $100 \%$ \\
\hline CORPUS UTERI & 2002 & 0.89 & 16 & 1988.5 & $50 \%$ & $50 \%$ \\
\hline CORPUS UTERI & 2003 & 0.99 & 11 & 1989.5 & $64 \%$ & $64 \%$ \\
\hline CORPUS UTERI & 2004 & 0.90 & 20 & 1988.2 & $45 \%$ & $45 \%$ \\
\hline CORPUS UTERI & 2005 & 1.02 & 25 & 1988.6 & $52 \%$ & $52 \%$ \\
\hline CORPUS UTERI & 2006 & 0.93 & 22 & 1988.5 & $50 \%$ & $50 \%$ \\
\hline HEAD \& NECK & 2002 & 7.67 & 49 & 1987.7 & $35 \%$ & $33 \%$ \\
\hline
\end{tabular}


Appendix Table 3

French cancer data

\begin{tabular}{|c|c|c|c|c|c|c|}
\hline Cancer site & Year & \begin{tabular}{|l} 
Age- \\
adjusted \\
mortality \\
rate (per \\
100,000 \\
pop)
\end{tabular} & $\begin{array}{l}\text { Number of } \\
\text { patients in } \\
\text { IMS } \\
\text { sample }\end{array}$ & \begin{tabular}{|l} 
Weighted \\
mean world \\
launch year
\end{tabular} & $\begin{array}{l}\text { post1985 } \\
\%\end{array}$ & \begin{tabular}{|l|} 
post1990 \\
$\%$
\end{tabular} \\
\hline HEAD \& NECK & 2003 & 7.35 & 62 & 1987.2 & $32 \%$ & $31 \%$ \\
\hline HEAD \& NECK & 2004 & 6.95 & 55 & 1986.7 & $22 \%$ & $18 \%$ \\
\hline HEAD \& NECK & 2005 & 6.72 & 105 & 1988.7 & $42 \%$ & $39 \%$ \\
\hline HEAD \& NECK & 2006 & 6.35 & 108 & 1988.8 & $43 \%$ & $40 \%$ \\
\hline HODGKINS DISEASE & 2002 & 0.46 & 88 & 1971.4 & $2 \%$ & $0 \%$ \\
\hline HODGKINS DISEASE & 2003 & 0.46 & 132 & 1971.4 & $2 \%$ & $0 \%$ \\
\hline HODGKINS DISEASE & 2004 & 0.48 & 201 & 1971.5 & $3 \%$ & $0 \%$ \\
\hline HODGKINS DISEASE & 2005 & 0.44 & 208 & 1971.5 & $3 \%$ & $0 \%$ \\
\hline HODGKINS DISEASE & 2006 & 0.43 & 205 & 1971.9 & $5 \%$ & $0 \%$ \\
\hline KIDNEY & 2003 & 5.17 & 3 & 1971.0 & $0 \%$ & $0 \%$ \\
\hline KIDNEY & 2004 & 4.91 & 5 & 1971.0 & $0 \%$ & $0 \%$ \\
\hline KIDNEY & 2005 & 4.94 & 6 & 1971.0 & $0 \%$ & $0 \%$ \\
\hline KIDNEY & 2006 & 4.80 & 6 & 1971.0 & $0 \%$ & $0 \%$ \\
\hline LIVER & 2002 & 11.63 & 38 & 1993.1 & $92 \%$ & $92 \%$ \\
\hline LIVER & 2003 & 11.66 & 47 & 1993.3 & $91 \%$ & $91 \%$ \\
\hline LIVER & 2004 & 11.48 & 42 & 1995.3 & $100 \%$ & $100 \%$ \\
\hline LIVER & 2005 & 11.65 & 55 & 1989.4 & $71 \%$ & $71 \%$ \\
\hline LIVER & 2006 & 11.55 & 61 & 1990.1 & $75 \%$ & $75 \%$ \\
\hline LUNG & 2002 & 41.89 & 533 & 1990.6 & $80 \%$ & $47 \%$ \\
\hline LUNG & 2003 & 42.98 & 724 & 1990.8 & $79 \%$ & $48 \%$ \\
\hline LUNG & 2004 & 43.22 & 739 & 1991.4 & $83 \%$ & $57 \%$ \\
\hline LUNG & 2005 & 44.09 & 1080 & 1991.6 & $78 \%$ & $56 \%$ \\
\hline LUNG & 2006 & 43.81 & 1194 & 1991.5 & $77 \%$ & $54 \%$ \\
\hline M.MYELOMA \& MALIG PLAS & 2002 & 3.92 & 85 & 1971.0 & $0 \%$ & $0 \%$ \\
\hline M.MYELOMA \& MALIG PLAS & 2003 & 4.07 & 69 & 1971.0 & $0 \%$ & $0 \%$ \\
\hline M.MYELOMA \& MALIG PLAS & 2004 & 3.73 & 79 & 1971.0 & $0 \%$ & $0 \%$ \\
\hline M.MYELOMA \& MALIG PLAS & 2005 & 3.79 & 83 & 1971.0 & $0 \%$ & $0 \%$ \\
\hline M.MYELOMA \& MALIG PLAS & 2006 & 3.73 & 85 & 1971.3 & $1 \%$ & $1 \%$ \\
\hline MELANOMA & 2002 & 2.32 & 3 & 1999.0 & $100 \%$ & $100 \%$ \\
\hline MELANOMA & 2003 & 2.36 & 2 & 1999.0 & $100 \%$ & $100 \%$ \\
\hline MELANOMA & 2004 & 2.32 & 3 & 1996.7 & $100 \%$ & $100 \%$ \\
\hline MELANOMA & 2005 & 2.41 & 10 & 1996.6 & $100 \%$ & $90 \%$ \\
\hline MELANOMA & 2006 & 2.41 & 8 & 1995.1 & $100 \%$ & $88 \%$ \\
\hline $\mathrm{NHL}$ & 2002 & 7.19 & 303 & 1971.9 & $0 \%$ & $0 \%$ \\
\hline$\overline{\mathrm{NHL}}$ & 2003 & 6.81 & 361 & 1971.6 & $1 \%$ & $1 \%$ \\
\hline$\overline{\mathrm{NHL}}$ & 2004 & 6.65 & 455 & 1971.7 & $0 \%$ & $0 \%$ \\
\hline $\mathrm{NHL}$ & 2005 & 6.56 & 553 & 1972.2 & $2 \%$ & $2 \%$ \\
\hline$\overline{\mathrm{NHL}}$ & 2006 & 6.22 & 573 & 1972.3 & $3 \%$ & $2 \%$ \\
\hline OESOPHAGUS & 2002 & 6.99 & 10 & 1987.9 & $50 \%$ & $10 \%$ \\
\hline OESOPHAGUS & 2003 & 6.59 & 7 & 1986.1 & $29 \%$ & $0 \%$ \\
\hline OESOPHAGUS & 2004 & 6.23 & 11 & 1986.3 & $18 \%$ & $9 \%$ \\
\hline OESOPHAGUS & 2005 & 6.22 & 23 & 1989.5 & $61 \%$ & $39 \%$ \\
\hline OESOPHAGUS & 2006 & 5.94 & 26 & 1989.9 & $62 \%$ & $42 \%$ \\
\hline OVARIAN & 2002 & 5.53 & 226 & 1988.5 & $48 \%$ & $48 \%$ \\
\hline OVARIAN & 2003 & 5.35 & 231 & 1988.5 & $48 \%$ & $48 \%$ \\
\hline OVARIAN & 2004 & 5.23 & 313 & 1988.5 & $50 \%$ & $50 \%$ \\
\hline
\end{tabular}


Appendix Table 3

French cancer data

\begin{tabular}{|l|r|r|r|r|r|r|}
\hline Cancer site & Year & $\begin{array}{l}\text { Age- } \\
\text { adjusted } \\
\text { mortality } \\
\text { rate (per } \\
100,000 \\
\text { pop) }\end{array}$ & $\begin{array}{l}\text { Number of } \\
\text { patients in } \\
\text { ImS } \\
\text { sample }\end{array}$ & $\begin{array}{l}\text { Weighted } \\
\text { mean world } \\
\text { launch year }\end{array}$ & $\begin{array}{l}\text { post1985 } \\
\%\end{array}$ & \multicolumn{1}{l}{$\begin{array}{l}\text { post1990 } \\
\%\end{array}$} \\
\hline OVARIAN & 2005 & 5.27 & 398 & 1988.4 & $47 \%$ & $47 \%$ \\
\hline OVARIAN & 2006 & 5.17 & 366 & 1988.4 & $47 \%$ & $47 \%$ \\
\hline PANCREAS & 2002 & 12.44 & 106 & 1995.0 & $99 \%$ & $99 \%$ \\
\hline PANCREAS & 2003 & 12.25 & 130 & 1995.0 & $100 \%$ & $100 \%$ \\
\hline PANCREAS & 2004 & 12.52 & 180 & 1994.9 & $99 \%$ & $99 \%$ \\
\hline PANCREAS & 2005 & 12.76 & 200 & 1995.0 & $99 \%$ & $99 \%$ \\
\hline PANCREAS & 2006 & 12.74 & 203 & 1994.9 & $99 \%$ & $99 \%$ \\
\hline PROSTATE & 2002 & 15.53 & 23 & 1994.7 & $100 \%$ & $96 \%$ \\
\hline PROSTATE & 2003 & 15.64 & 36 & 1993.2 & $100 \%$ & $69 \%$ \\
\hline PROSTATE & 2004 & 14.87 & 58 & 1993.9 & $100 \%$ & $81 \%$ \\
\hline PROSTATE & 2005 & 14.46 & 60 & 1994.8 & $100 \%$ & $97 \%$ \\
\hline PROSTATE & 2006 & 13.64 & 69 & 1994.8 & $100 \%$ & $97 \%$ \\
\hline STOMACH & 2002 & 8.57 & 19 & 1986.5 & $21 \%$ & $21 \%$ \\
\hline STOMACH & 2003 & 8.04 & 12 & 1990.1 & $42 \%$ & $42 \%$ \\
\hline STOMACH & 2004 & 8.03 & 18 & 1993.4 & $72 \%$ & $72 \%$ \\
\hline STOMACH & 2005 & 7.69 & 52 & 1994.2 & $75 \%$ & $75 \%$ \\
\hline STOMACH & 2006 & 7.35 & 51 & 1993.2 & $69 \%$ & $69 \%$ \\
\hline THYROID & 2005 & 0.62 & 2 & 1993.5 & $100 \%$ & $100 \%$ \\
\hline THYROID & 2006 & 0.67 & 2 & 1993.5 & $100 \%$ & $100 \%$ \\
\hline
\end{tabular}




\section{CESifo Working Paper Series}

for full list see www.cesifo-group.org/wp

(address: Poschingerstr. 5, 81679 Munich, Germany, office@cesifo.de)

3033 Steven Brakman, Robert Inklaar and Charles van Marrewijk, Structural Change in OECD Comparative Advantage, April 2010

3034 Dirk Schindler and Guttorm Schjelderup, Multinationals, Minority Ownership and TaxEfficient Financing Structures, April 2010

3035 Christian Lessmann and Gunther Markwardt, Decentralization and Foreign Aid Effectiveness: Do Aid Modality and Federal Design Matter in Poverty Alleviation?, April 2010

3036 Eva Deuchert and Conny Wunsch, Evaluating Nationwide Health Interventions when Standard Before-After Doesn't Work: Malawi's ITN Distribution Program, April 2010

3037 Eric A. Hanushek and Ludger Woessmann, The Economics of International Differences in Educational Achievement, April 2010

3038 Frederick van der Ploeg, Aggressive Oil Extraction and Precautionary Saving: Coping with Volatility, April 2010

3039 Ainura Uzagalieva, Evžen Kočenda and Antonio Menezes, Technological Imitation and Innovation in New European Union Markets, April 2010

3040 Nicolas Sauter, Jan Walliser and Joachim Winter, Tax Incentives, Bequest Motives, and the Demand for Life Insurance: Evidence from two Natural Experiments in Germany, April 2010

3041 Matthias Wrede, Multinational Capital Structure and Tax Competition, April 2010

3042 Burkhard Heer and Alfred Maussner, A Note on the Computation of the Equity Premium and the Market Value of Firm Equity, April 2010

3043 Kristiina Huttunen, Jukka Pirttilä and Roope Uusitalo, The Employment Effects of Low-Wage Subsidies, May 2010

3044 Matthias Kalkuhl and Ottmar Edenhofer, Prices vs. Quantities and the Intertemporal Dynamics of the Climate Rent, May 2010

3045 Bruno S. Frey and Lasse Steiner, Pay as you Go: A New Proposal for Museum Pricing, May 2010

3046 Henning Bohn and Charles Stuart, Population under a Cap on Greenhouse Gas Emissions, May 2010

3047 Balázs Égert and Rafal Kierzenkowski, Exports and Property Prices in France: Are they Connected?, May 2010 
3048 Thomas Eichner and Thorsten Upmann, Tax-Competition with Involuntary Unemployment, May 2010

3049 Taiji Furusawa, Kazumi Hori and Ian Wooton, A Race beyond the Bottom: The Nature of Bidding for a Firm, May 2010

3050 Xavier Vives, Competition and Stability in Banking, May 2010

3051 Thomas Aronsson and Erkki Koskela, Redistributive Income Taxation under Outsourcing and Foreign Direct Investment, May 2010

3052 Michael Melvin and Duncan Shand, Active Currency Investing and Performance Benchmarks, May 2010

3053 Sören Blomquist and Laurent Simula, Marginal Deadweight Loss when the Income Tax is Nonlinear, May 2010

3054 Lukas Menkhoff, Carol L. Osler and Maik Schmeling, Limit-Order Submission Strategies under Asymmetric Information, May 2010

3055 M. Hashem Pesaran and Alexander Chudik, Econometric Analysis of High Dimensional VARs Featuring a Dominant Unit, May 2010

3056 Rabah Arezki and Frederick van der Ploeg, Do Natural Resources Depress Income Per Capita?, May 2010

3057 Joseph Plasmans and Ruslan Lukach, The Patterns of Inter-firm and Inter-industry Knowledge Flows in the Netherlands, May 2010

3058 Jenny E. Ligthart and Sebastian E. V. Werner, Has the Euro Affected the Choice of Invoicing Currency?, May 2010

3059 Håkan Selin, Marginal Tax Rates and Tax-Favoured Pension Savings of the SelfEmployed - Evidence from Sweden, May 2010

3060 Richard Cornes, Roger Hartley and Yuji Tamura, A New Approach to Solving Production-Appropriation Games with Many Heterogeneous Players, May 2010

3061 Ronald MacDonald and Flávio Vieira, A Panel Data Investigation of Real Exchange Rate Misalignment and Growth, May 2010

3062 Thomas Eichner and Rüdiger Pethig, Efficient Management of Insecure Fossil Fuel Imports through Taxing(!) Domestic Green Energy?, May 2010

3063 Vít Bubák, Evžen Kočenda and Filip Žikeš, Volatility Transmission in Emerging European Foreign Exchange Markets, May 2010

3064 Leonid V. Azarnert, Après nous le Déluge: Fertility and the Intensity of Struggle against Immigration, May 2010 
3065 William E. Becker, William H. Greene and John J. Siegfried, Do Undergraduate Majors or Ph.D. Students Affect Faculty Size?, May 2010

3066 Johannes Becker, Strategic Trade Policy through the Tax System, May 2010

3067 Omer Biran and Françoise Forges, Core-stable Rings in Auctions with Independent Private Values, May 2010

3068 Torben M. Andersen, Why do Scandinavians Work?, May 2010

3069 Andrey Launov and Klaus Wälde, Estimating Incentive and Welfare Effects of NonStationary Unemployment Benefits, May 2010

3070 Simon Gächter, Benedikt Herrmann and Christian Thöni, Culture and Cooperation, June 2010

3071 Mehmet Bac and Eren Inci, The Old-Boy Network and the Quality of Entrepreneurs, June 2010

3072 Krisztina Molnár and Sergio Santoro, Optimal Monetary Policy when Agents are Learning, June 2010

3073 Marcel Boyer and Donatella Porrini, Optimal Liability Sharing and Court Errors: An Exploratory Analysis, June 2010

3074 Guglielmo Maria Caporale, Roman Matousek and Chris Stewart, EU Banks Rating Assignments: Is there Heterogeneity between New and Old Member Countries? June 2010

3075 Assaf Razin and Efraim Sadka, Fiscal and Migration Competition, June 2010

3076 Shafik Hebous, Martin Ruf and Alfons Weichenrieder, The Effects of Taxation on the Location Decision of Multinational Firms: M\&A vs. Greenfield Investments, June 2010

3077 Alessandro Cigno, How to Deal with Covert Child Labour, and Give Children an Effective Education, in a Poor Developing Country: An Optimal Taxation Problem with Moral Hazard, June 2010

3078 Bruno S. Frey and Lasse Steiner, World Heritage List: Does it Make Sense?, June 2010

3079 Henning Bohn, The Economic Consequences of Rising U.S. Government Debt: Privileges at Risk, June 2010

3080 Rebeca Jiménez-Rodriguez, Amalia Morales-Zumaquero and Balázs Égert, The VARying Effect of Foreign Shocks in Central and Eastern Europe, June 2010

3081 Stephane Dees, M. Hashem Pesaran, L. Vanessa Smith and Ron P. Smith, Supply, Demand and Monetary Policy Shocks in a Multi-Country New Keynesian Model, June 2010 
3082 Sara Amoroso, Peter Kort, Bertrand Melenberg, Joseph Plasmans and Mark Vancauteren, Firm Level Productivity under Imperfect Competition in Output and Labor Markets, June 2010

3083 Thomas Eichner and Rüdiger Pethig, International Carbon Emissions Trading and Strategic Incentives to Subsidize Green Energy, June 2010

3084 Henri Fraisse, Labour Disputes and the Game of Legal Representation, June 2010

3085 Andrzej Baniak and Peter Grajzl, Interjurisdictional Linkages and the Scope for Interventionist Legal Harmonization, June 2010

3086 Oliver Falck and Ludger Woessmann, School Competition and Students' Entrepreneurial Intentions: International Evidence Using Historical Catholic Roots of Private Schooling, June 2010

3087 Bernd Hayo and Stefan Voigt, Determinants of Constitutional Change: Why do Countries Change their Form of Government?, June 2010

3088 Momi Dahan and Michel Strawczynski, Fiscal Rules and Composition Bias in OECD Countries, June 2010

3089 Marcel Fratzscher and Julien Reynaud, IMF Surveillance and Financial Markets - A Political Economy Analysis, June 2010

3090 Michel Beine, Elisabetta Lodigiani and Robert Vermeulen, Remittances and Financial Openness, June 2010

3091 Sebastian Kube and Christian Traxler, The Interaction of Legal and Social Norm Enforcement, June 2010

3092 Volker Grossmann, Thomas M. Steger and Timo Trimborn, Quantifying Optimal Growth Policy, June 2010

3093 Huw David Dixon, A Unified Framework for Using Micro-Data to Compare Dynamic Wage and Price Setting Models, June 2010

3094 Helmuth Cremer, Firouz Gahvari and Pierre Pestieau, Accidental Bequests: A Curse for the Rich and a Boon for the Poor, June 2010

3095 Frank Lichtenberg, The Contribution of Pharmaceutical Innovation to Longevity Growth in Germany and France, June 2010 